\title{
A Novel Mouse Model of Inflammatory Bowel Disease Links Mammalian Target of Rapamycin-Dependent Hyperproliferation of Colonic Epithelium to Inflammation-Associated Tumorigenesis
}

\author{
Lin Deng, ${ }^{*}$ Jin-Feng Zhou, ${ }^{*}$ Rani S. Sellers, ${ }^{\dagger}$ \\ Jiu-Feng Li, ${ }^{\ddagger}$ Andrew V. Nguyen, ${ }^{\S}$ Yubao Wang, ${ }^{\dagger}$ \\ Amos Orlofsky, ${ }^{\dagger}$ Qiang Liu, ${ }^{\dagger}$ David A. Hume, ${ }^{\pi}$ \\ Jeffrey W. Pollard, ${ }^{\ddagger}$ Leonard Augenlicht, ${ }^{*}$ \\ and Elaine Y. Lin*

\begin{abstract}
From the Department of Medicine, Oncology Division," Albert Einstein Cancer Center; Montefiore Medical Center, the Departments of Pathology, ${ }^{\dagger}$ and Developmental and Molecular Biology, ${ }^{\ddagger}$ Albert Einstein College of Medicine, Bronx, New York; the Department of Biological Sciences and Geology, Queensborough-CUNY, Bayside, New York; and The Roslin Institute, "The University of Edinburgh, Roslin, Midlothian, United Kingdom
\end{abstract}

Inflammatory bowel disease (IBD) is a high-risk condition for human colorectal cancer. However, our mechanistic understanding of the link between inflammation and tumorigenesis in the colon is limited. Here we established a novel mouse model of colitisassociated cancer by genetically inactivating signal transducer and activator of transcription 3 (Stat3) in macrophages, with partial deletion in other myeloid and lymphoid cells. Inflammation developed in the colon of mutant mice spontaneously, and tumor lesions, including invasive carcinoma, arose in the inflamed region of the intestine with a frequency similar to that observed in human IBD patients. The development of both inflammation and tumors in the mutant mice required the presence of microflora. Indeed, inflammation was associated with disruption of colonic homeostasis, fulminant epithelial/tumor cell proliferation, and activation of the mammalian target of rapamycin (mTOR)-Stat3 pathway in epithelial and tumor cells. The activation of this pathway was essential for both the excess proliferation of epithelial/tumor cells and the disruption of colonic homeostasis in the mutant mice. Notably, a similar abnormal up-regulation of mTOR-Stat3 signaling was consistently observed in the colonic epithelial cells of human IBD patients with active disease. These studies demonstrate a novel mouse model of IBD-colorectal cancer progression in which disrupted immune regulation, mTOR-Stat3 signaling, and epithelial hyperproliferation are integrated and simultaneously linked to the development of malignancy. (Am J Pathol 2010, 176:952-967; DOI: 10.2353/ajpath.2010.090622)

Chronic inflammation in the intestine ranks among the top three high-risk conditions for colorectal cancer. ${ }^{1}$ In contrast to the other high-risk conditions, the hereditary syndromes of familial adenomatous polyposis and hereditary nonpolyposis colorectal cancer, in which the genetic predispositions have been identified, the mechanistic link between inflammation and tumorigenesis is still largely unknown. ${ }^{1}$

IBD is thought to be an unique modulation of the intestinal mucosal immune response determined by a complex interplay of genetic, microbial, and environmental factors. ${ }^{2}$ Animal models that mimic human IBD and its associated colorectal cancers have contributed to recent progress in the understanding of mucosal immunity and its dysregulation in tumorigenesis. ${ }^{3}$ A number of widely used models involve chemically induced inflammationassociated colorectal cancers, initiated by injecting mice

Supported by a Montefiore Medical Center New Research Initiative Award, a Miriam Mandel Faculty Scholar Award, the National Cancer Institute (NCl) (R01-94173, P01-CA100324, and U54-CA100926), and Albert Einstein Cancer Center Core grant P30-CA13330. The content is solely the responsibility of the authors and does not necessarily represent the official views of the $\mathrm{NCl}$

A guest editor acted as editor-in-chief for this manuscript. No person at Thomas Jefferson University or Albert Einstein College of Medicine was involved in the peer review process or final disposition for this article.

Accepted for publication October 1, 2009

Supplemental material for this article can be found on http://ajp. amjpathol.org.

Address reprint requests to Elaine Y. Lin, M.D., Ph.D., Department of Medicine, Oncology Division, Montefiore Medical Center, 111 E. 210th St., Bronx, NY 10467. E-mail: elin@montefiore.org. 
with carcinogens such as azoxymethane and/or introducing chemical irritants such as dextran sulfate sodium. ${ }^{3}$ Such treatments lead to acute inflammation in the intestine promoted by mucosal damage induced by the chemical, rather than chronic inflammation as observed in patients with IBD, and therefore may not recapitulate stochastic events involved in inflammation-associated cancers in the human. ${ }^{4}$

An alternative approach is to model IBD by genetic modifications that favor the development of chronic intestinal inflammation. Signaling through interleukin (IL) 10, an anti-inflammatory cytokine, has been targeted, because evidence indicates that this cytokine is important in maintaining the hyporesponsive state of the intestinal mucosa to normal bacterial microflora. ${ }^{5}$ Sequence variants or polymorphisms in the $1 \mathrm{~L}-10$ gene have been reported to contribute to IBD susceptibility, ${ }^{6-8}$ indicating that interference with IL-10 regulation may make an important contribution to the etiology of IBD. Indeed, inflammation and tumors develop in the colon of $1 \mathrm{~L}-10^{-I-}$ mice in a manner dependent on the presence of intestinal microflora. ${ }^{9}$ However, because $I L-10$ deletion is present in all cells in these mice, it is difficult in this model to distinguish effects due to dysregulation of stromal and immune cells from effects arising from IL-10 mutation in the epithelium.

To address this issue, attempts have been made to inactivate IL-10 signaling more specifically in cells of the immune system. Signal transducer and activator of transcription 3 (Stat3) plays a major role in Janus tyrosine kinase/Stat signaling induced by IL-10. ${ }^{10}$ Mice with inactivation of Stat3 targeted by interferon-responsive Mx1Cre to multiple types of cells including macrophages and gut epithelial cells ${ }^{11}$ or targeted to myeloid cells with LysM-Cre, developed colitis in the intestine. ${ }^{12}$ However, unlike in $\mathrm{L}-10^{-/-}$mice, targeting of Stat3 inactivation in these mice was not reported to cause tumor formation, ${ }^{11,12}$ suggesting that additional factor(s) are required for prompting tumor development in the colon in the setting of an inflammatory response. In this regard, although IL-10 plays a major role in myeloid cells, the cytokine also inhibits activation and function of $\mathrm{T}$ cells, granulocytes, B cells, and natural killer cells, ${ }^{13}$ although mice with T lymphocyte-specific depletion of Stat3 did not develop either colitis or colonic tumors. ${ }^{14}$

We therefore tested the effect of the conditional inactivation of $S t a t 3^{\text {flox }}$ genes in immune cells using Cre driven by the colony-stimulating factor- 1 receptor promoter. ${ }^{15,16}$ This inactivated Stat3 in both myeloid and lymphoid cells, including macrophages, lymphocytes, and granulocytes, which produced not only a dramatic inflammatory response of the intestine but also eventual malignant tumor formation at a frequency similar to that observed in human IBD patients. These phenotypes were completely dependent on the intestinal microflora. This novel mouse model of human IBD recapitulates the increased probability of tumor development in the colon, an important clinical phenotype in human IBD. ${ }^{1}$ Furthermore, using this model we present the first evidence that the inflammation-associated hyperproliferation of colonic epithelial cells is dependent on the activation of signaling through an mTOR-Stat3 pathway.

\section{Materials and Methods}

\section{Mice}

All procedures were conducted in accordance with $\mathrm{Na}$ tional Institutes of Health regulations concerning use and care of experimental animals and approved by the Albert Einstein College of Medicine animal use committee. All of the mice were housed in the pathogen-free barrier facility at Albert Einstein College of Medicine.

\section{Stat3-IKO Mice}

To establish the transgenic construct for $T g(C s f 1$-iCre)jwp, the improved Cre (iCre) sequence ${ }^{17}$ was inserted into Apal and Notl sites using blunt-ended ligation downstream from the colony-stimulating factor- 1 receptor promoter. ${ }^{16}$ The transgenic mice were generated using standard methods in the Transgenic Mouse Facility at Albert Einstein College of Medicine. Tg(Csf1r-iCre)jwp mice were identified by PCR-based genotyping with the following primers: F1, 5'-CAGGGCCTTCTCCACACCAGC-3'; and F2, 5'-CTGGCTGTGAAGACCATC-3'. Stat3 $3^{\text {flox/flox }}$ mice (C57BL/6) were kindly provided by Dr. Colin Stewart (National Institutes of Health), ${ }^{18}$ and mice were identified using a standard PCR-based genotyping procedure with following primers: F1, 5'-GCTGCCAACAGCCACTGCCCCAG-3'; F2, 5'-GAAGGCAGGTCTCTCTGGTGCTTC3'; and F3, 5'-CAGAACCAGGCGGCTCGTGTGCG-3'. The PCR reaction yields a 140-bp product from wild-type, a 260-bp product from the flox, or a 379-bp product from the flox-depleted sequence of the Stat3 gene. The mice used in the experiments were at or more than three generations of backcrossing to C57BL/6 mice.

\section{Flow Cytometry}

Bone marrow-derived macrophages (BMMs) were prepared as described previously with minor changes. ${ }^{19}$ Antibodies used were R-phycoerythrin- or allophycocyanin-conjugated rat anti-mouse F4/80 (Invitrogen, Carlsbad, CA), R-phycoerythrin-conjugated rat anti-mouse CD3 (Invitrogen), R-phycoerythrin-conjugated rat antimouse Ly6G (BD Pharmingen, San Diego, CA), PerCPconjugated rat anti-CD11b (BD Pharmingen), mouse antimouse Stat3 (IgG2a) (Cell Signaling Technology, Danvers, $\mathrm{CT}$ ), and Alexa Fluor 488-conjugated goat anti-mouse IgG2a. For each reaction, isotopic nonspecific antibody for the primary antibody and secondary antibody only controls were used.

\section{Western Blotting Analysis}

Western blotting analysis was performed following the standard procedure. Antibodies were anti-Stat3 (1:2000, 
Cell Signaling), anti- $\beta$-actin ( $2 \mathrm{ng} / \mathrm{ml}$, Sigma-Aldrich, St. Louis, MO), and anti-Bcl-xL (1:1000, Cell Signaling).

\section{Human Colon Tissue}

Human colon sections from four individuals with active IBD were provided by the Pathology Department at Montefiore Medical Center (institutional review board exempted protocol 09-03-096X). The tissue array for human normal and sporadic colon cancer was from Imgenex (IMH-359, Imgenex, San Diego, CA).

\section{Histological Analysis}

Colons were prepared as "Swiss rolls," fixed in 10\% formalin, and then paraffin-embedded. Sections were stained with H\&E. The degree of inflammation and tumors of the colon sections were evaluated by R.S.S., a veterinary pathologist in the Albert Einstein Cancer Center Histology Core Facility. Inflammation was scored as follows: 0 , no inflammation; 1 , minimal; 2 , mild; 3, moderate; 4, marked; and 5, severe. Lesions were classified (evaluated in regard to the consensus statement of mouse model of intestinal cancers, with modifications ${ }^{20}$ ) as follows. Hyperplasia was characterized by thickened mucosa with elongated crypts. Crypts consist of goblet cells and morphologically normal epithelium with nuclear morphology and polarity similar to those of the normal controls. Dysplasia (hyperplasia with dysplasia and inflammation) was classified by thickened mucosa with elongated, irregularly branched glands that contain epithelium with cytological and nuclear atypia including loss of differentiation (goblet cells), polarity, and enlarged nuclei. Areas of the intestine with inflammation graded as moderate or greater generally had some degree of dysplasia. Dysplasia was graded in five levels similar to the inflammation score described above. Carcinoma is distinguished by tumor cell invasion into submucosa. Specific features also include the presence of irregular glands, desmoplasia, and cell loss as well as multiple invading sites in the invading mucosa. ${ }^{20}$ The leukocytic infiltration and injury scores were determined following the procedure of Xiao el al. ${ }^{21}$ For goblet cell identification, tissue sections were stained with $1 \%$ Alcian blue $(\mathrm{pH} 2.5)$ and $0.1 \%$ neutral red following standard procedures. For quantitative histological analysis, the stained tissue sections were photographed to produce TIFF images using an Olympus IX70 microscope and a Sesicam QEcooled charge-coupled device camera. The entire inflamed colon was photographed, and at least three mice per group were analyzed. Positively stained areas were measured and normalized with the areas of nuclei in the same fields using ImageJ software as described previously. ${ }^{22}$ Mucosal thickness was measured as the length from the bottom of the crypt to the tip of the gland in TIFF images using ImageJ. Complete glands of colon sections (approximately seven per mouse) were measured in the inflamed region of Stat3-IKO mice and the corresponding region in Stat3 $3^{\text {flox/flox }}$ mice.

\section{Yellow Fluorescence Protein Detection}

Tissue sections from Tg(Csf1r-iCre)jwp.Rosa-YFP mice were prepared as described previously. ${ }^{22}$ Sections were counterstained with 4',6'-diamidino-2-phenylindole and imaged using a Leica SP2 AOBS laser scanning confocal microscope in the Analytical Image Facility at Albert Einstein College of Medicine. The yellow color of yellow fluorescence protein (YFP) was converted to green using Adobe Photoshop.

\section{Immunohistochemistry}

Tissues for immunohistochemistry $(\mathrm{IHC})$ experiments were fixed with $10 \%$ formalin, except for those for F4/80 $I H C$, which were fixed in Zinc fixative (BD Pharmingen), using standard procedures. Antibodies were $0.1 \mu \mathrm{g} / \mathrm{ml}$ anti-F4/80 (Invitrogen), $3 \mu \mathrm{g} / \mathrm{ml}$ anti-CD3 (DakoCytomation, Carpinteria, CA), $5 \mu \mathrm{g} / \mathrm{ml}$ anti-Ly-6G, 1:200 of antiKi-67, $4 \mu \mathrm{g} / \mathrm{ml}$ anti-pStat3 (Tyr $\left.{ }^{705}\right), 1: 100$ for anti-cyclin D1 (Lab Vision, Fremont, CA), $78 \mathrm{ng} / \mathrm{ml}$ anti-CD31 (BD Pharmingen), 1:50 for anti-pStat3 (Ser-727), 1:400 for anti-pS6, and 1:400 for anti-Survivin (Cell Signaling). The standard IHC procedure provided by Cell Signaling was used.

\section{Antibiotic Treatment}

The published procedure for treatment of mice with a combination of antibiotics (vancomycin, neomycin, metronidazole, and ampicillin [VNMA]) and the detection of bacteria in stool was used. ${ }^{21}$ Mice were treated with 10 $\mathrm{mg} / \mathrm{kg}$ daily Everolimus (Sigma-Aldrich) or 1\% dimethyl sulfoxide/saline for 3 days by gavages.

\section{Results}

\section{Stat3 Conditionally Depleted Mice}

To determine the effect of blocking Stat3-mediated signaling in macrophages, we established a transgenic mouse line, $T g$ (Csf1r-iCre)jwp, in which expression of Cre was under control of the colony-stimulating factor-1 receptor promoter (Csf1r or Fms). ${ }^{15,16}$ An improved Cre (iCre) sequence, based on mammalian codon usage, ${ }^{17}$ was used for the transgenic construct to maximize efficiency of target excision. After introduction into FVB embryos, one of three founder mice transmitted the transgene to its offspring, which were phenotypically normal. The $T g(C s f 1 r-i C r e) j w p$ transgene was then crossed into Rosa-26-YFP reporter mice to examine iCre-dependent deletion at this marker locus. Analysis of $\mathrm{Tg}(\mathrm{Csf1}$-iCre) jwp+1-. Rosa26-YFP mice revealed that the YFP signal was detected only in mice that carried the transgene. Signal was seen in various tissues, including liver, spleen, intestine, heart, kidney, and muscle; in each tissue, expression was found in cells with characteristics consistent with macrophages/dendritic cells (supplemental Figure S1A, see http://ajp.amjpathol.org). Consistent with these data, fluorescence-activated cell sorter 

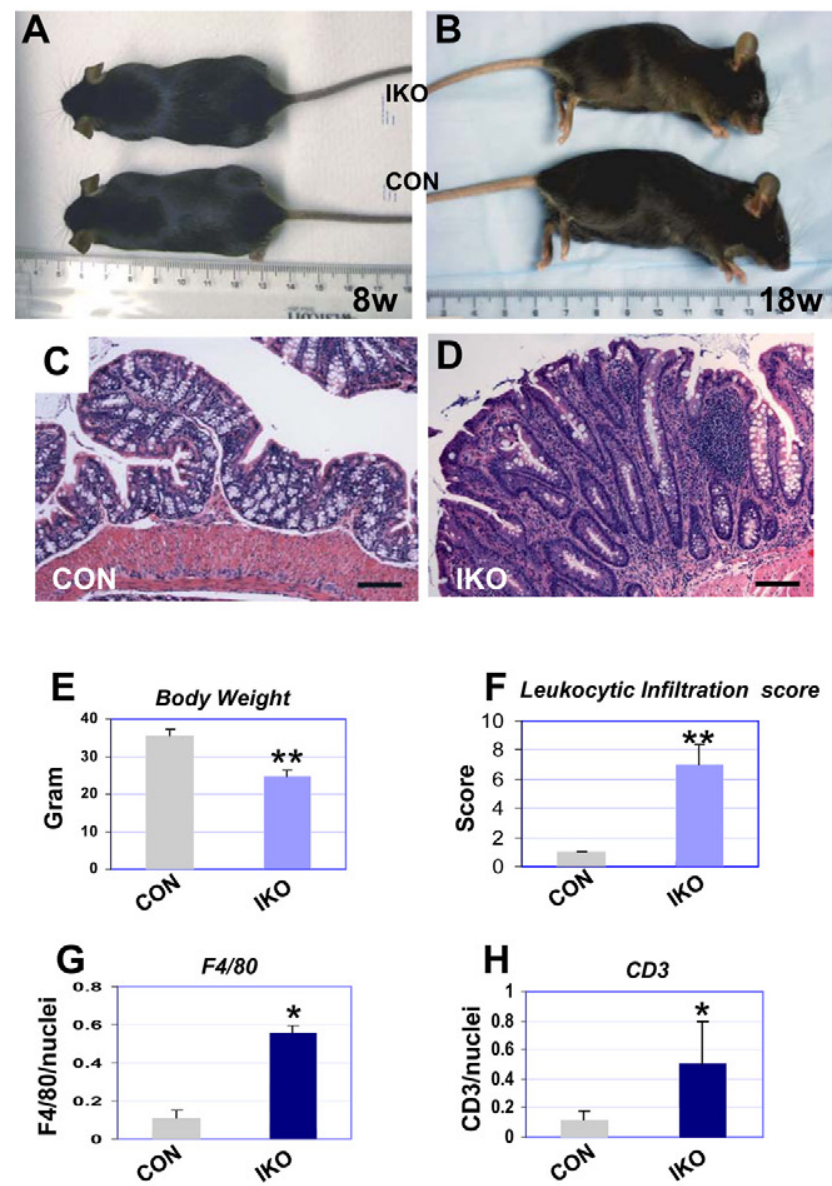
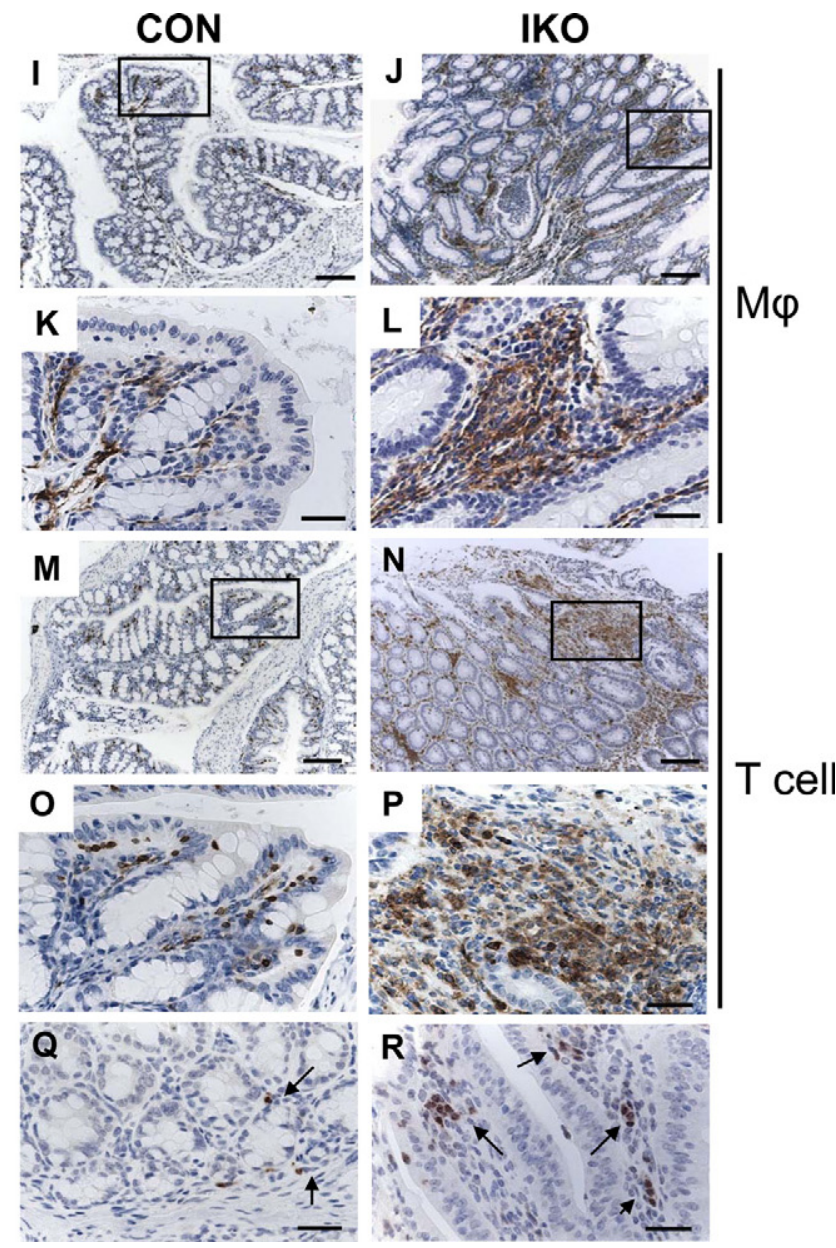

Figure 1. Inactivation of Stat3-induced inflammation in colon. $\mathbf{A}$ and B: Mouse size. Stat $3-\mathrm{IKO}(\mathrm{IKO})$ and Stat ${ }^{\mathrm{f} / \mathrm{f}}$ mice $(\mathrm{CON})$ at $8(\mathbf{A})$ and $18(\mathbf{B})$ weeks of age as indicated. $\mathbf{C}$ and $\mathbf{D}$ : Colon histology. H\&E-stained colon sections from a Stat $3^{\mathrm{f} / \mathrm{f}}$ control $(\mathbf{C})$ or a Stat 3 -IKO $(\mathbf{D}) \mathrm{mouse}$. Scale bar $=100 \mu \mathrm{m}$ E: Body weight. Stat3-IKO mice were collected between 24 and 29 weeks of age and compared with age-matched Stat $3^{\mathrm{f} / \mathrm{f}}$ littermates $(\mathrm{CON}[n=6]$ versus IKO $[n=5]$; unpaired $t$-test, ${ }^{* *} P=0.0013$ ). F: Leukocytic infiltration score. The score in the colon of Stat 3 -IKO and Stat ${ }^{\mathrm{f} / \mathrm{f}}$ littermates (unpaired $t$-test, ${ }^{* *} P=0.0021, n=3$ ). G or H: Quantitative analysis of $\mathrm{F} 4 / 80$ or CD3 immunohistochemical analysis, respectively (unpaired $t$-test, ${ }^{*} P=0.0012$ for $\mathbf{G}$ and $P=0.035$ for $\mathbf{H}, n=3$ ). I-R: Immunohistochemical analysis for infiltrated leukocytes in colon. I-L: Immunochemical analysis for macrophage (M $\varphi$ ) $\left(\mathrm{F} 4 / 80^{+}\right)$for Stat $3^{\mathrm{f} / \mathrm{f}}(\mathbf{I}$ and $\mathbf{K})$ or Stat3-IKO colons $(\mathbf{J}$ and $\mathbf{L})$. M-P: Immunohistochemical analysis for T lymphocytes $\left(\mathrm{CD} 3^{+}\right)$for Stat $3^{\mathrm{f} / \mathrm{f}}(\mathbf{M}$ and $\mathbf{O})$ or Stat3-IKO colons ( $\mathbf{N}$ and $\mathbf{P}$ ). The inset in $\mathbf{I}, \mathbf{J}, \mathbf{M}$, or $\mathbf{N}$ is shown in $\mathbf{K}, \mathbf{L}, \mathbf{O}$, or $\mathbf{P}$ in higher magnification, respectively. $\mathbf{Q}$ and $\mathbf{R}$ : Immunohistochemical analysis for granulocyte $\left(\right.$ Ly $\left.6 G^{+}\right)$for Stat $3^{\mathrm{f} / \mathrm{f}}(\mathbf{Q})$ or Stat3-IKO colons $(\mathbf{R})$. Arrows point to some positive cells. Scale bars: $100 \mu \mathrm{m}(\mathbf{I}, \mathbf{J}, \mathbf{M}$, and $\mathbf{N}) ; 30 \mu \mathrm{m}$ $(\mathbf{K}, \mathbf{L}$ or $\mathbf{O}-\mathbf{R})$

analysis revealed YFP signal in $~ 80 \%$ of BMMs (supplemental Figure S1Ba, see http://ajp.amjpathol.org). However, a YFP signal was also found in $~ 50 \%$ of bone marrow granulocytes and splenic T lymphocytes (Supplemental Figure $\mathrm{S} 1 \mathrm{Bb}$ and $\mathrm{c}$, see http://ajp.amjpathol. org). The transgene was then crossed into mice that were Stat ${ }^{\text {flox/flox }}$, targeting excision of exons 16 to 21 of the Stat3 gene, thus inactivating the protein. ${ }^{18}$ Consistent with the above data, efficient deletion in Stat3 was ob-

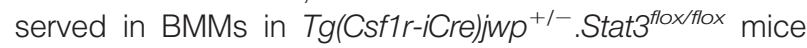
(Supplemental Figure S1C, see http://ajp.amjpathol. org), reducing the level of Stat3 protein in BMMs of these mice to $<20 \%$ of that present in BMMs from Tg(Csf1riCre)jwp ${ }^{-1-}$.Stat3 $3^{\text {flox/flox }}$ controls (Supplemental Figure S1D, see http://ajp.amjpathol.org). Fluorescence-activated cell sorter analysis confirmed efficient Stat3 depletion in BMMs and relatively lower efficiency ( $50 \%)$ in granulocytes and $\mathrm{T}$ or $\mathrm{B}$ lymphocytes isolated from Tg(Csf1r-iCre)jwp ${ }^{+1-}$.Stat ${ }^{\text {flox/flox }}$ compared with those from Stat3 ${ }^{\text {flox/flox }}$ mice (data not shown). Because Stat3 depletion was found in inflammatory cells rather than in the intestinal epithelium (described below), Tg(Csf1riCre)jwp ${ }^{+/-}$.Stat3 ${ }^{\text {flox/flox }}$ mice were referred to as Stat3IKO. Because no Stat3 depletion was found in Tg(Csf1r$i C r e) j w p^{-1-}$.Stat $3^{\text {flox/flox }}$ mice that did not carry the transgene and they were phenotypically normal, these were subsequently used as the wild-type control (ie, Stat3 $^{\mathrm{f} / \mathrm{f}}$ controls).

\section{Development of Spontaneous Colitis in Stat3-IKO Mice}

Stat3-IKO mice (on a mixed background of FVB/C57BL/6 backcrossed for at least three generations to Stat3 $3^{\text {flox/flox }}$ mice [C57BL/6]) were obtained at the expected Mendelian ratio with no abnormalities at birth or within the first few weeks after parturition (Figure 1A), indicating that 
Table 1. Comparison of Tumor Development in Stat $3^{\mathrm{f} / \mathrm{f}}$ and Stat3-IKO Mice

\begin{tabular}{cccccc}
\hline Mice (8-39 Weeks) & Inflammation & No lesion & Hyperplasia & Dysplasia & Carcinoma \\
\hline Stat3-IKO & $20 / 21$ & $6 / 19(32 \%)$ & $13 / 19(68 \%)$ & $12 / 19(63 \%)$ & $3 / 19(16 \%)$ \\
Stat3 $^{f / f}$ & $1 / 21$ & $17 / 17(100 \%)$ & 0 & 0 & 0 \\
\hline
\end{tabular}
0.0001

inactivation of Stat3 by the transgene did not detectably alter embryonic or early development. However, $20 \%$ of Stat3-IKO mice developed pronounced colitis at 8 weeks of age, which increased to $\sim 50 \%$ by 18 to 20 weeks of age. These mice exhibited persistent diarrhea, bloody feces, and weight loss. The remaining mutant mice, although without these prominent symptoms, also were less physically active and had significantly lower body weights at older ages compared with age-matched Stat $^{\text {f/f }}$ controls (Figure 1, B and E). Histological analysis of Stat3-IKO with or without evident colitis revealed increased leukocytic infiltration and intestinal mucosal thickening compared with Stat3 $3^{\mathrm{f} / \mathrm{f}}$ littermates (Figure 1, C versus $\mathrm{D}$ ), predominantly in the proximal colon and cecum, without gross histological abnormalities in the small intestine (data not shown). Consistent with these observations, the leukocytic infiltration score (degree of leukocytic infiltration and increased mucosal thickness) ${ }^{21}$ was significantly higher in the Stat3-IKO colons compared with control colons (Figure 1F). Twenty of 21 Stat3-IKO mice aged 8 to 39 weeks developed inflammation in the

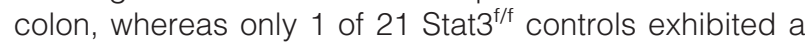
mild increase in leukocytic infiltration (Table 1, Fisher's exact test, $P<0.0001$ ).

Macrophages ( $\mathrm{F} 4 / 80^{+}$cells) markedly increased in the colon of Stat3-IKO mice (Figure $1, \mathrm{I}$ and $\mathrm{K}$ versus $\mathrm{J}$ and $\mathrm{L})$. There was also a striking increase in $\mathrm{CD}^{+} \mathrm{T}$-cells (Figure $1, \mathrm{M}$ and $\mathrm{O}$ versus $\mathrm{N}$ and $\mathrm{P}$ ) and a moderate increase in granulocytes (Figure 1, Q versus R). Quantitative analysis by $\mathrm{IHC}$ showed a significantly higher density of $\mathrm{F}_{4} / 80^{+}$and $\mathrm{CD}^{+}$cells in the proximal colon of Stat3-IKO mice (Figure 1, G and $\mathrm{H}$, respectively). Thus, inactivation of Stat3 in Stat3-IKO mice was associated with an inflammatory reaction specifically in the colon.

\section{Tumor Development in Inflamed Colon and Cecum in Stat3-IKO Mice}

Visible polyps were found in the inflamed areas of the proximal colon (Figure 2A, arrows) and cecum (data not shown). As with tumors found in human IBD, ${ }^{23}$ most of the lesions in Stat3-IKO mice were "flat" with a broad base (Figure 2C) or morphologically similar to "dysplasia-associated lesions or masses." ${ }^{24}$ Carcinoma was identified in some of these nodules, with tumor invasion to submucosa or even muscularis external (Figure 2D, arrow). In addition to its invasion into the submucosa or deeper, carcinoma was identified by specific features described in the consensus report and recommendations for pathology of mouse models of intestinal cancer. ${ }^{20}$ These included the presence of irregular or angulated glands with cell loss in invasive components (Figure 2E, ar- rows), desmoplasia (Figure 2D and Supplemental Figure S2a and c, see http://ajp. amjpathol.org) and multiple invading mucosa (Supplemental Figure S2c, see http:// ajp.amjpathol.org). Further, cells in invasive glands exhibited severe atypia with discernible pleomorphism and loss of the basement membrane (Supplemental Figure S2b and d, see http://ajp. amjpathol.org). These features are distinct from hernias of colonic mucosa ${ }^{20}$ also found in the inflamed colon and cecum in Stat3-IKO mice (data not shown). In addition to carcinoma, hyperplasia (Figure 2, $\mathrm{H}-\mathrm{I}$ ) and dysplasia (Figure 2, J and $\mathrm{K}$ ) were identified in the inflamed intestine in Stat3-IKO mice as described in detail in Materials and Methods. Neoplastic lesions were found to be restricted to inflamed areas of the colon or cecum, with $63 \%$ of 8- to 39-week-old Stat3-IKO mice exhibiting dysplasia and $16 \%$ of Stat3-IKO mice developing carcinoma (Table 1). None of the age-matched Stat $3^{\mathrm{fff}}$ controls developed dysplasia or carcinoma, a highly significant difference between the groups (Fisher's exact test, $P<0.0001$ ). The dysplastic lesions were further graded 1 to 5 in regard to tumor progression, as described in Materials and Methods. There was a significant positive correlation between the grade of dysplasia and the degree of inflammation in the colon of Stat3-IKO mice (Figure 2L), demonstrating that colon tumor development in Stat3-IKO mice was closely associated with the presence of inflammation.

\section{Inflammation and Tumor Development in Stat3-IKO Colon Are Dependent on the Intestinal Microflora}

Disrupted interaction of the host immune system with the commensal microflora, a major component of the intestinal microenvironment that contributes to mucosal homeostasis, ${ }^{25}$ probably contributes to the development of human IBD. ${ }^{26}$ To determine whether inflammation and tumor development in Stat3-IKO mice were dependent on the intestinal microflora, Stat3-IKO and Stat $3^{\mathrm{fff}}$ control mice were treated with a combination of antibiotics (VNMA) to substantially reduce the bacterial content of the intestinal lumen. ${ }^{21}$ After 4.5 weeks of continuous administration of antibiotics through the drinking water, bacterial density in the stool of treated Stat3-IKO mice (Figure $3 \mathrm{C}$ ) or control mice (not shown) was markedly reduced compared with that of untreated Stat3 $3^{\mathrm{f} / \mathrm{f}}$ (Figure $3 \mathrm{~A}$ ) and Stat3-IKO mice (Figure 3B). Interestingly, higher density of bacteria was found in the stool of Stat3-IKO mice than in that of the Stat $3^{\mathrm{ff} f}$ controls, indicating that abnormal regulation of mucosal immunity may induce changes in microflora in colon (Figure 3, A versus B). Parallel to this reduction of bacteria, both inflammation and tumor de- 

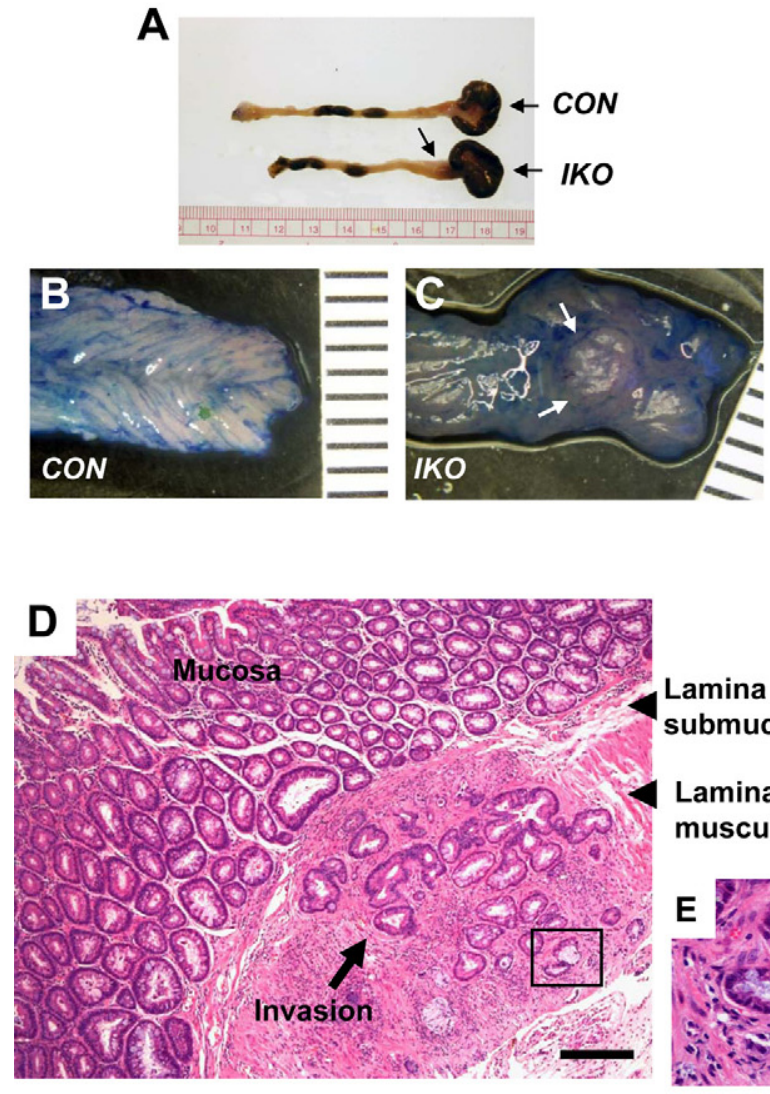

Lamina submucosae

Lamina muscularis

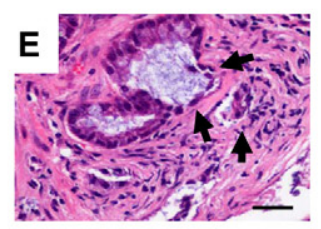

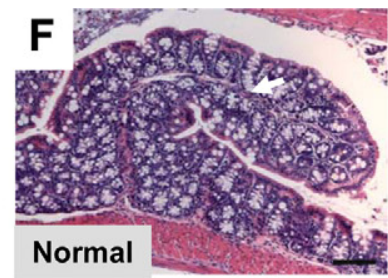
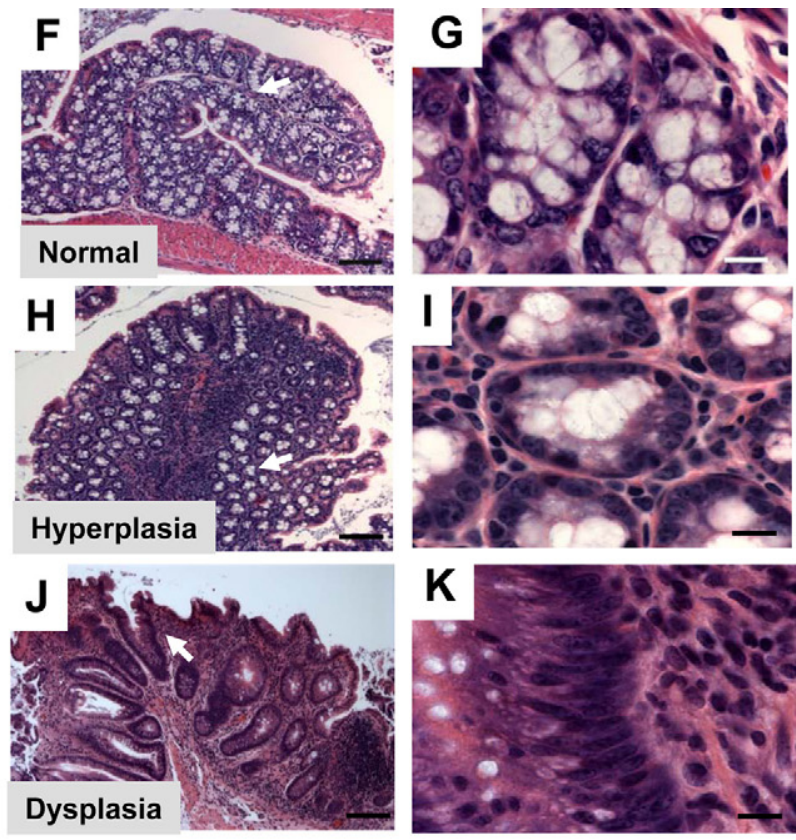

L Inflammation/tumor correlation

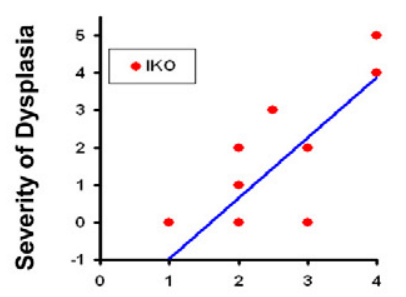

Degree of Inflammation

Figure 2. Tumors developed in the inflamed colon and cecum in Stat3-IKO mice. A-C: Visible nodules. Gross images of colon (A) from a Stat3-IKO (IKO, bottom) or a Stat $3^{\mathrm{f} / \mathrm{f}}\left(\mathrm{CON}\right.$, top) mouse at 19 weeks of age. The proximal end of the colon from the same Stat $3^{\mathrm{f} / \mathrm{f}}(\mathbf{B})$ or Stat $3-\mathrm{IKO}$ mouse $(\mathbf{C})$. Arrows in $\mathbf{C}$ point to the tumor nodules. $\mathbf{D}$ and $\mathbf{E}$ : Histology of carcinoma. H\&E staining of a nodule found in the inflamed colon of a Stat3-IKO mouse. D: The colon section with tumor invasion to muscularis externa as indicated. The inset in $\mathbf{D}$ is shown in $\mathbf{E}$ in higher magnification. The long arrow in $\mathbf{D}$ points to the invasive site and short arrows point to the histology of the colon. Arrows in $\mathbf{E}$ indicate cell loss in the invading component of the tumor. Scale bars: $200 \mu \mathrm{m}(\mathbf{D}) ; 30 \mu \mathrm{m}(\mathbf{E})$. F-K: Colon histology. Representative H\&E images of colon from a Stat ${ }^{\mathrm{f} / \mathrm{f}}(\mathbf{F}$ and $\mathbf{G})$ and Stat3-IKO mice $(\mathbf{H}-\mathbf{K})$ with hyperplasia ( $\mathbf{H}$ and $\mathbf{I}$ ) and dysplasia $(\mathbf{J}$ and $\mathbf{K}$ ). The area indicated by the arrow in $\mathbf{F}, \mathbf{H}$, or $\mathbf{J}$ is shown in $\mathbf{G}, \mathbf{I}$, or $\mathbf{K}$, respectively, in higher magnification. Scale bars: $100 \mu \mathrm{m}(\mathbf{F}, \mathbf{H}$, or $\mathbf{J}) ; 10 \mu \mathrm{m}(\mathbf{G}, \mathbf{I}$, or $\mathbf{K})$. L: Correlation between inflammation and tumor development. The severity of the dysplastic lesions and the degree of inflammation in the colon of Stat3-IKO mice from 9 to 39 weeks of age were plotted as individual points. Nonparametric Spearman correlation was used for statistical analysis: $r=0.8313, P<0.0001$.

velopment in the colon of VNMA-treated Stat3-IKO mice were significantly inhibited (Table 2). There was a notable lack of inflammation and reduction of mucosal thickness in the colon of VNMA-treated Stat3-IKO mice (Figure 3, E versus $F$ ), and the histopathology of the colonic mucosa of these mice was similar to the untreated Stat $3^{\mathrm{f} / \mathrm{f}}$ controls (Figure 3, D versus F). The leukocytic infiltration score and the infiltration of both macrophages and T lymphocytes were also markedly reduced (Figure 3, G-J, K, and $N)$. However, compared with those in untreated Stat ${ }^{f / f}$ control mice, infiltrated macrophages in the VNMAtreated Stat3-IKO mice were still significantly higher (Figure $3 \mathrm{M}, \mathrm{CON}$ versus $\mathrm{IKO}$ ), indicating that the treatment did not completely inhibit inflammation in the colon. The injury score, measured by the extent of loss of goblet cells in the crypt, ${ }^{21}$ was also consistently significantly higher in VNMA-treated Stat3-IKO colon compared with the Stat $^{\mathrm{f} / \mathrm{f}}$ control colon (Figure $3 \mathrm{~L}$, CON versus IKO).
Parallel to the reduction of inflammation, the development of colonic tumors was significantly reduced by antibiotic treatment: no tumors were found in any of the 11 Stat3-IKO mice from 21 to 27 weeks of age treated with antibiotics, and only 2 of these treated mice displayed mild inflammation and hyperplasia at the end of the treatment. The tumor incidence was significantly lower than that in untreated Stat3-IKO mice 27 weeks of age or younger (Table 2, $P<0.001$ ). These data indicate that the inflammation and tumor development in Stat3-IKO colon was dependent on the intestinal microflora. Further investigation may reveal the specific species of bacteria involved. Because a large percentage of Stat3-IKO at 21 weeks of age has developed dysplasia, the result also suggests that the reduction in inflammation by antibiotic treatment may cause a regression of the early stages of dysplasia and neoplasia (Table 2). However, the low frequency of carcinoma precluded determination of whether the treatment had an effect on established carcinomas. 

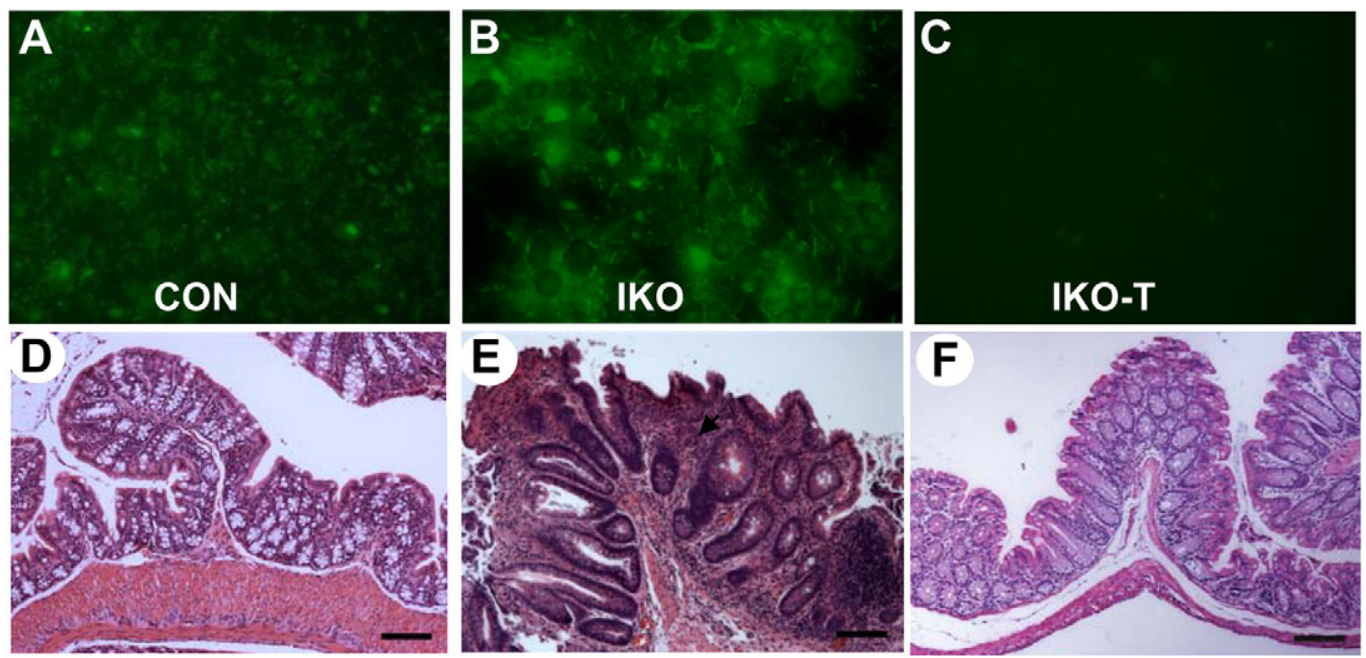

IKO
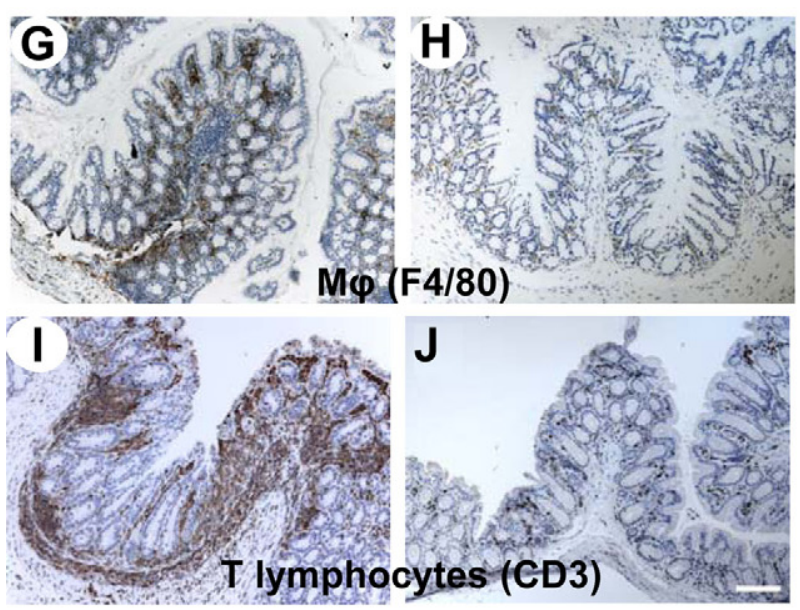

K

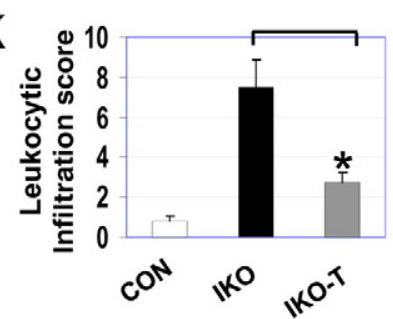

M

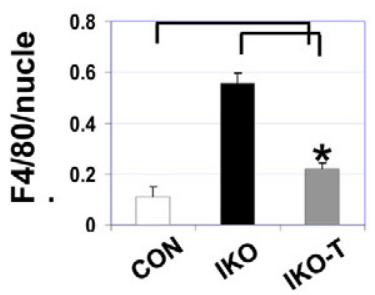

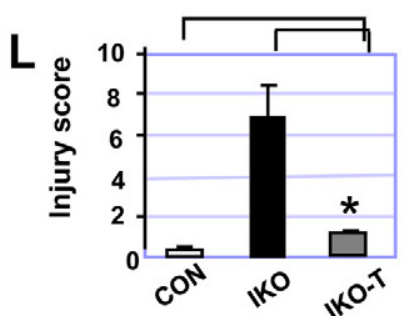

$\mathbf{N}$

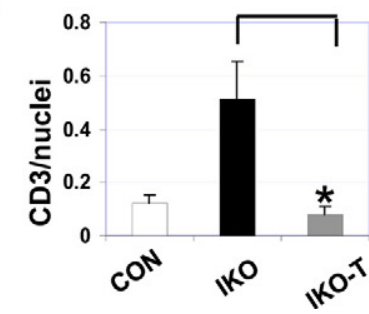

Figure 3. Inflammation and tumor development in Stat3-IKO colon is dependent on intestinal microflora. A-C: Bacterial density in stools of an untreated Stat $3^{\mathrm{f} / \mathrm{f}}$ (A), untreated Stat3-IKO (B), or a VNMA-treated Stat3-IKO (C) mouse. D-F: The correlated histology of the colon. Scale bar $=100 \mu$ m. Immunohistochemical analysis for macrophages (F4/80) ( $\mathbf{G}$ and $\mathbf{H}$ ) and T lymphocytes (CD3) (I and $\mathbf{J}$ ). Scale bar (in $\mathbf{J}$ for all of the images) $=100 \mu \mathrm{m}$. K: Comparison of leukocytic infiltration. *Unpaired $t$-test: IKO versus IKO-T, $P=0.005$; CON versus IKO-T, $P=0.174$. L: Epithelial injury score. *Unpaired $t$-test: IKO versus IKO-T, $P=0.019$ CON versus IKO-T, $P=0.0013$. M: Quantitative immunohistochemical analysis for F4/80. *Unpaired $t$-test: IKO versus IKO-T, $P<0.001$; CON versus IKO-T, $P=$ 0.047. N: Quantitative immunohistochemical analysis for CD3. *Unpaired $t$-test: IKO versus IKO-T, $P=0.023 ;$ CON versus IKO-T, $P=0.29$. CON, untreated Stat $3^{\mathrm{f} / \mathrm{f}}$, IKO, untreated Stat3-IKO and IKO-T, VNMA-treated Stat3-IKO mice.

\section{Impact of Inflammation on Intestinal}

Homeostasis

To explore potential mechanisms by which inflammation might have promoted tumorigenesis in the intestine of Stat3-IKO mice, we examined the impact of inflammation on colonic epithelial cell proliferation, apoptosis, and differentiation. As noted, there was a prominent alteration in mucosal thickness of the proximal colon from $120 \mu \mathrm{m}$ in controls to $>400 \mu \mathrm{m}$ in inflamed regions in Stat3-IKO mice (Figure 4A). CoIonic stem cells normally reside in the lower crypts, giving rise to transit-amplifying cells, which migrate toward the lumen, differentiating along lineages with specific functions. ${ }^{27}$ Proliferating $\mathrm{Ki}-67^{+}$stem and transit-amplifying cells are thus normally restricted to the

Table 2. Effect of Antibiotic Treatment

\begin{tabular}{lccccc}
\hline \multicolumn{1}{c}{ Mice } & Inflammation & No lesion & Hyperplasia & Dysplasia & Carcinoma \\
\hline Stat3-IKO (8-27 weeks) & $14 / 15(93 \%)$ & $5 / 15(33 \%)$ & $10 / 15(67 \%)$ & $10 / 15(67 \%)$ & $3 / 15(20 \%)$ \\
Stat3-IKO VNMA-treated (21-27 weeks) & $3 / 11(27 \%)$ & $9 / 11(82 \%)$ & $2 / 11(18 \%)$ & 0 & 0 \\
Stat3 $^{\text {f/f }}$ (8-27 weeks) & $1 / 16(6 \%)$ & $16 / 16(100 \%)$ & 0 & 0 & 0 \\
\hline
\end{tabular}

Statistic analysis: Fisher's exact test, two-tailed for inflammation: Stat3-IKO VNMA treated versus untreated, $P<0.001$; Stat3 IKO VNMA treated versus Stat3/f/f untreated, $P=0.55$; for tumor development (dysplasia): Stat3-IKO VNMA treated versus untreated, $P<0.001$; for tumor development (carcinoma): Stat3-IKO VNMA-treated versus untreated, $P=0.175$. 
A

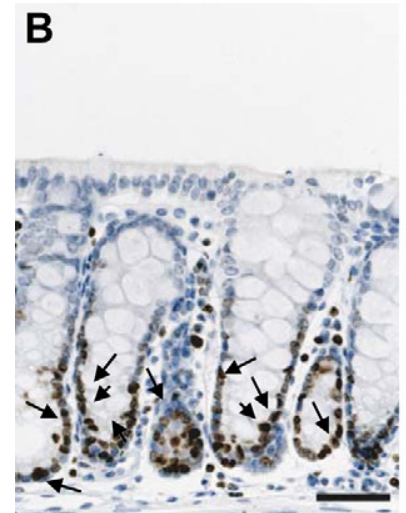

CON
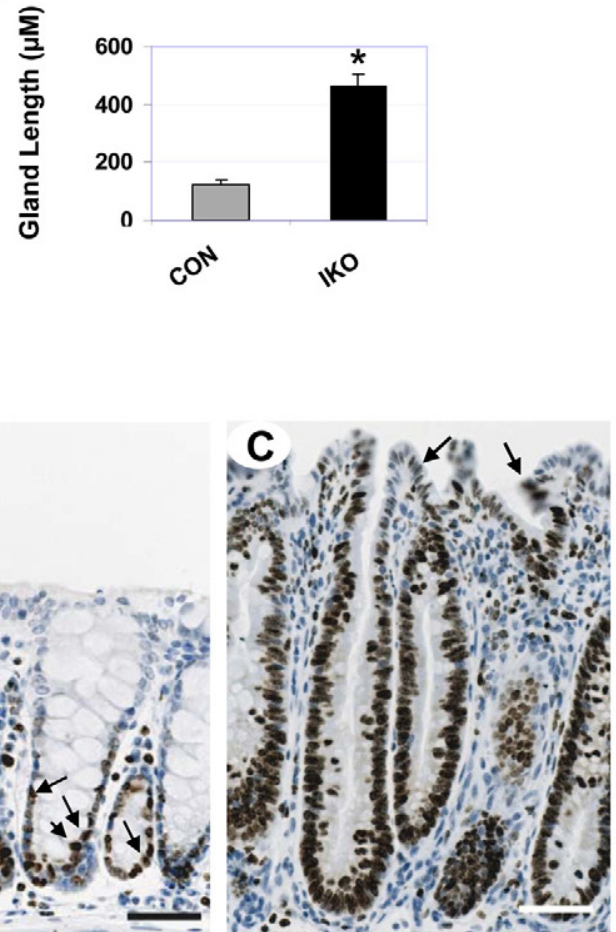

IKO
CON
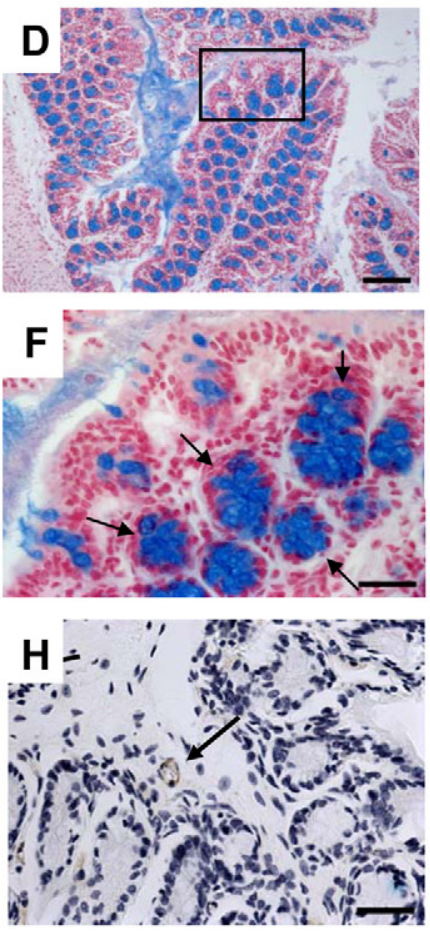

J

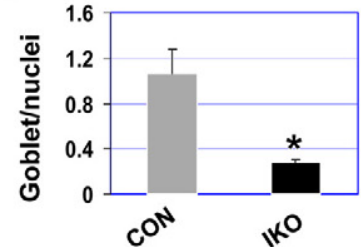

IKO
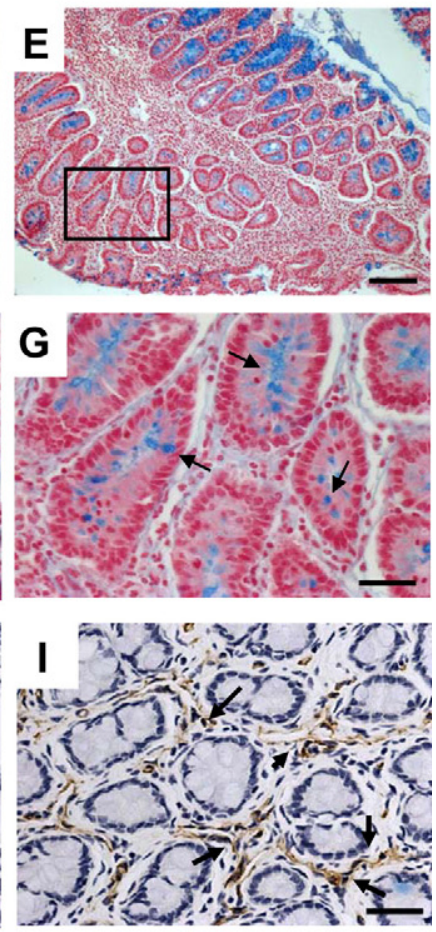

K

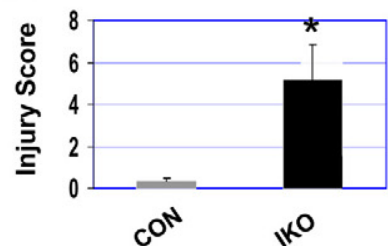

Figure 4. The impact of inflammation on epithelial biology. A: Mucosal thickness. The thickness of the colonic mucosa was measured on the images of H\&E stained slides as described in Materials and Methods. CON, Stat $3^{\mathrm{f} / \mathrm{f}}(n=3)$; IKO, Stat3-IKO $(n=5)$ mice $\left(\right.$ unpaired $t$-test, $\left.{ }^{*} P=0.0009\right)$. B and $\mathbf{C}$ : Epithelium proliferation. Immunochemical analysis for Ki- 67 for a Stat $3^{\mathrm{f} / \mathrm{f}}(\mathbf{B})$ and Stat $3-\mathrm{IKO}$ colon $(\mathbf{C})$. Arrows in $\mathbf{B}$ indicate Ki-67 ${ }^{+}$cells and in $\mathbf{C}$ indicate Ki- $67^{+}$cells at the tip of the gland. Scale bar $=50 \mu \mathrm{m}$. D-G: Alcian blue/neutral red-stained colon sections from a Stat ${ }^{\mathrm{f} / \mathrm{f}}(\mathbf{D}$ and $\mathbf{F})$ and a Stat3-IKO mouse ( $\mathbf{E}$ and $\mathbf{G}$ ). The insets in $\mathbf{D}$ or $\mathbf{F}$ are shown in higher magnification in $\mathbf{F}$ and $\mathbf{G}$. Goblet cells are stained in blue, as indicated by arrows. $\mathbf{H}$ and $\mathbf{I}$ : Immunochemical analysis for endothelial marker CD31 for colon sections from a Stat $3^{\mathrm{f} / \mathrm{f}}$ (H) or a Stat3-IKO mouse (I). Arrows point to some of the CD31-positive capillaries. Scale bars: $100 \mu \mathrm{m}$ (D and $\mathbf{E}) ; 30 \mu \mathrm{m}(\mathbf{F}-\mathbf{I})$. J: Quantitative analysis of goblet cell density in colon. The normalized density of goblet cells in the colon of Stat $3^{\mathrm{f} / \mathrm{f}}(\mathrm{CON})$ and Stat3-IKO (IKO) mice were plotted (*unpaired $t$-test, $P=0.02, n=3$ ). K: Epithelial injury score. The injury scores in the colon of Stat3-IKO (IKO) $(n=5)$ and Stat $3^{\mathrm{f} / \mathrm{f}}$ mice (CON) $(n=6)$ ("unpaired $t$-test, $\left.P=0.011\right)$ were measured as described in Materials and Methods.

lower half of the gland, as shown in Figure 4B. In the inflamed areas of the colon in Stat3-IKO mice, Ki-67 cells were found along the entire length of the crypt, including the uppermost region adjacent to the lumen (Figure $4 \mathrm{C}$, arrows), demonstrating a persistent proliferation of colonic epithelium responding to the inflammation. No obvious difference in the death of epithelial cells was found when the colons of Stat3-IKO mice were compared with those of Stat $3^{\mathrm{f} / \mathrm{f}}$ controls (data not shown).

Mature glands of the colon consist of several cell populations, including goblet cells, which can produce and secrete mucin and are a major component of the epithelium. ${ }^{27}$ Using Alcian blue/neutral red staining to visualize these cells, we found a significant decrease in goblet cell density in the inflamed colon of Stat3-IKO mice compared with equivalent regions in the Stat $3^{\mathrm{f} / \mathrm{f}}$ controls (Figure 4, D and F versus $E$ and $G$ ). This finding was confirmed by quantitative analysis (Figure 4J). Consistent with these data, the injury score ${ }^{21}$ was an order of magnitude higher in Stat3-IKO mice than in controls (Figure 4K), demonstrating perturbed cell differentiation in the colon of Stat3-IKO mice. The depletion of goblet cells is interesting in light of the fact that genetic ablation of this lineage and the mucin they produce leads to tumor formation associated with an inflammatory response. ${ }^{28,29}$ In addition, using an antibody that recognizes the endothelial cell-specific marker, CD31, we observed a markedly increased vessel density in the inflamed colon in Stat3-IKO mice (Figure 4, H versus I), suggesting increased angiogenesis in the inflamed tissue. Overall, these findings indicate a significant alteration of homeostasis of the colonic epithelium within the large intestine of the Stat3-IKO mice, including a marked increase in proliferating epithelial cells and a loss of colonic epithelial differentiation. 

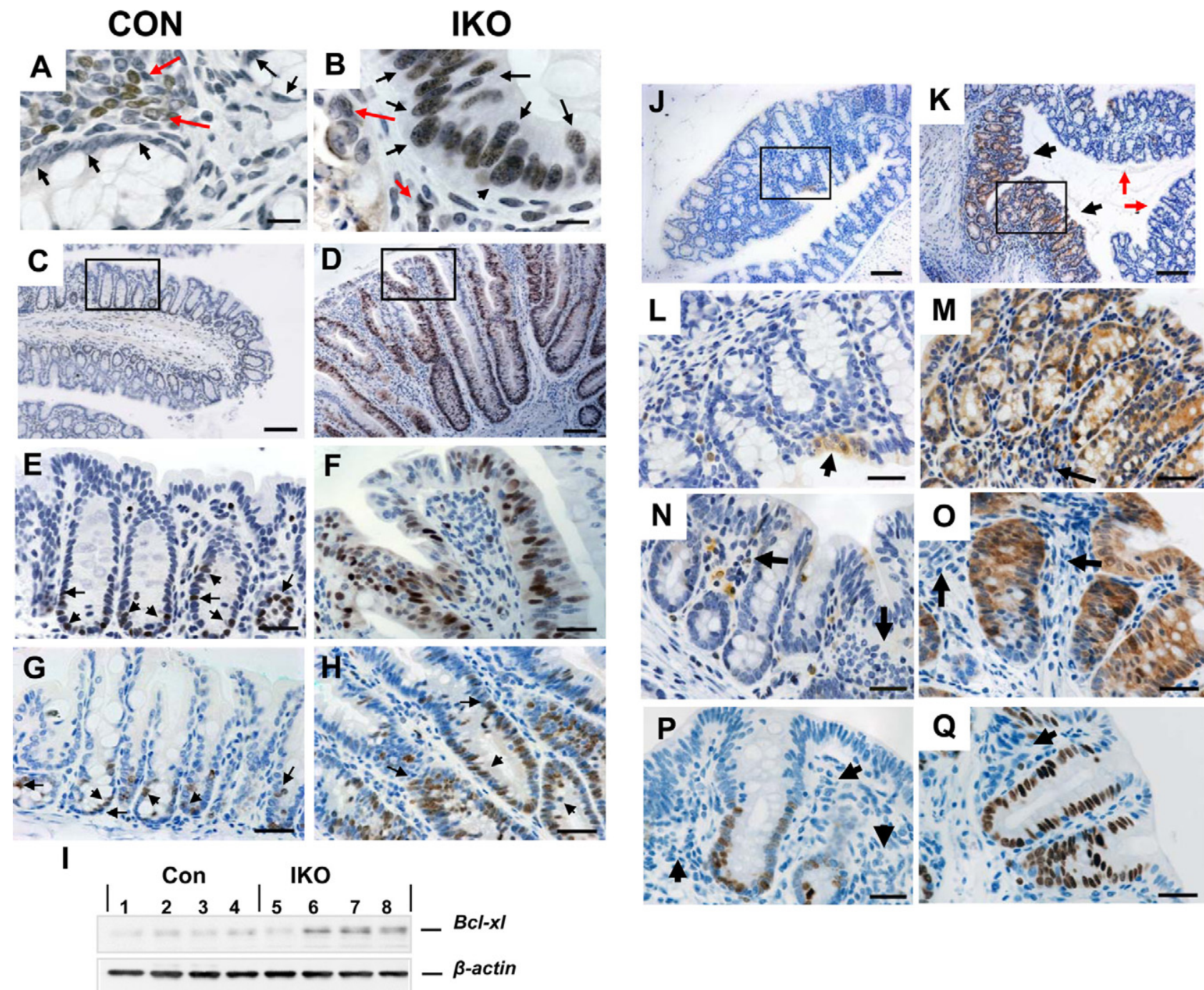

Figure 5. Activation of Stat 3 and mTOR pathways in epithelium of inflamed colon. A-H: Activation of Stat 3 pathway. Immunochemical analysis for phosphorylated Stat 3 $\left(\mathrm{Tyr}^{705}\right.$ ) (A and $\mathbf{B}$ ). Red arrows indicate phosphorylated Stat3 (pStat3) ( $\mathrm{Tyr}^{705}$ ) positively stained stromal cells and black arrows indicate positively stained intestinal epithelial or tumor cells. Immunochemical analysis for cyclin D1 (C-F). The inset in $\mathbf{C}$ or $\mathbf{D}$ is shown in $\mathbf{E}$ or $\mathbf{F}$ in higher magnification. Arrows in $\mathbf{E}$ point to cyclin D1-positive cells in the crypt area of the normal colon. Immunochemical analysis for Survivin ( $\mathbf{G}$ and $\mathbf{H})$. Arrows point to Survivin-positive cells. Samples from Stat ${ }^{\mathrm{f} / \mathrm{f}}$ $(\mathrm{CON})$ and age-matched Stat3-IKO mice (IKO) are indicated. Scale bars: $10 \mu \mathrm{m}(\mathbf{A}$ and $\mathbf{B}) ; 100 \mu \mathrm{m}(\mathbf{C}$ and $\mathbf{D}) ; 30 \mu \mathrm{m}(\mathbf{E}-\mathbf{H})$. I: Western blotting analysis of Bcl-xL expression in colonic mucosa from Stat $3^{\mathrm{f} / \mathrm{f}}(\mathrm{Con}$, lanes $1-4)$ and age-matched Stat3-IKO mice (IKO, lanes $5-8$ ). The same sample was blotted by anti- $\beta$-actin antibody. J-O: Activation of mTOR in epithelium of inflamed colon. J-M: Immunochemical analysis for pS6 in the colon of a Stat $3^{\mathrm{f} / \mathrm{f}} \mathrm{mouse}(\mathbf{J}$ and $\mathbf{L})$ and an age-matched Stat3-IKO mouse ( $\mathbf{K}$ and $\mathbf{M}$ ). The inset in $\mathbf{J}$ or $\mathbf{K}$ is shown in $\mathbf{L}$ or $\mathbf{M}$ in higher magnification. Arrow in $\mathbf{L}$ points to limited pS6-positive epithelial cells in normal colon. Black arrows in $\mathbf{K}$ point to the inflamed region of colon that contains a high density of pS6-positive epithelial cells and red arrows point to the adjacent less inflamed area that contains fewer pS6-positive cells. Arrow in $\mathbf{M}$ indicates the high density of leukocytic infiltration in the inflamed region of colon. $\mathbf{N}$ and $\mathbf{~ O : ~ I m m u n o c h e m i c a l ~ a n a l y s i s ~ f o r ~ p S 6 ~ f o r ~}$ colon sections from a Stat3-IKO mouse treated with Everolimus (N) and an untreated Stat3-IKO littermate (O). Arrows point to infiltrated leukocytes. $\mathbf{P}$ and $\mathbf{Q}$ Immunochemical analysis for Ki-67 in colon sections from a Stat3-IKO mouse treated with Everolimus (P) and an untreated Stat3-IKO littermate (Q). Arrows indicate the high density of leukocytic infiltration adjacent to the colonic glands. Scale bars: $100 \mu \mathrm{m} / \mathrm{L}(\mathbf{J}$ and $\mathbf{K}) ; 30 \mu \mathrm{m}(\mathbf{L}-\mathbf{Q})$.

\section{Role of Stat3 and mTOR Signaling in \\ Tumorigenesis in the Inflamed Colon of Stat3-IKO Mice}

In studies directed to oncogenic pathways that may promote tumorigenesis in the colon of Stat3-IKO mice, we found that both Stat3 and mTOR are highly activated in the epithelial and tumor cells in the inflamed colon. When the colon of Stat $3^{\mathrm{f} / \mathrm{f}}$ mice was examined using an antibody that recognizes the activated form of Stat3 (phosphorylated at $\mathrm{Tyr}^{705}$ ), colonic epithelium was negative for activated Stat3 (Figure 5A, black arrows), whereas some mononuclear stromal cells were positive (Figure 5A, red arrows). In contrast, colonic epithelial and tumor cells in Stat3-IKO mice (in which the Stat3 gene remains structurally intact) were positive for nuclear activated Stat3, with more intense staining in the enlarged nuclei of tumor cells (Figure 5B, black arrows). In addition to the epithelial cells, a high density of infiltrated mononuclear cells with activated Stat3 was also observed in the inflamed colon of Stat3-IKO mice (Supplemental Figure S3, see http://ajp.amjpathol.org), suggesting that Stat3 is not inactivated in some subsets of myeloid and lymphoid cells involved in inflammation. Consistent with constitutive activation of Stat3 in colonic epithelium, we observed increased epithelial expression of Stat3 target genes, in- 
cluding cyclin D1, Survivin, and BCL-xL, which are functionally important in driving cell proliferation and survival as well as neoplastic transformation. ${ }^{30}$ In the colon of control mice, cyclin D1 was expressed principally in the crypt epithelial cells (Figure 5, C and E, arrows), whereas in Stat3-IKO mice expression was elevated in the majority of epithelial cells throughout the entire hyperplastic gland in inflamed areas of the colon, as well as in dysplastic regions (Figure 5, D and F) and in carcinoma (data not shown). Another Stat3 target gene, Survivin, is a key regulator of mitosis and apoptosis and is tightly regulated in normal colon. ${ }^{31,32}$ In the colon of Stat $3^{\text {f/f }}$ control mice, only a few Survivin-positive cells ( $\sim 5$ positive cells/ gland) were found in crypts of the colonic glands (Figure $5 \mathrm{G}$, arrows). In contrast, a large increase in Survivinpositive epithelial cells was evident in the inflamed colon and tumors of Stat3-IKO mice compared with controls ( $\sim 50$ positive cells/gland) (Figure $5 \mathrm{H}$ ). Finally, we observed elevated expression of another Stat3-regulated apoptosis inhibitor, $\mathrm{BCL}-\mathrm{xL}$, in the mucosa of the proximal colon of Stat3-IKO mice compared with that in controls (Figure 5I). These results suggest that inflammation in Stat3-IKO mice may promote abnormal proliferation and survival of colonic epithelial cells through the activation of Stat3 and associated pathways in these cells.

The serine/threonine kinase mTOR is a key effector for many cellular pathways, and dysregulation of mTOR signaling has been found in various human cancers. ${ }^{33}$ To determine whether abnormal activation of MTOR was induced in the inflamed intestine in Stat3-IKO mice, we examined the phosphorylation of S6 ribosomal protein (Ser-235/236) (pS6), which is catalyzed by S6 kinase in a mTOR-dependent manner. ${ }^{34}$ Few pS6-positive epithelial cells were found in normal colon, whereas strong expression of pS6 was found in colonic epithelial cells in the inflamed region of Stat3-IKO colon (Figure 5, J and L versus $\mathrm{K}$ and $\mathrm{M}$ ). This elevated expression of pS6 was restricted to areas with a high density of leukocytic infiltration (Figure 5K, black arrows), whereas very few pS6positive cells were found in adjacent areas with milder infiltration (Figure 5K, red arrows).

To determine whether the activation of MTOR was functionally linked to the disruption of colonic homeostasis in the inflamed colon, Stat3-IKO and Stat $3^{f / f}$ mice (9 to 12 weeks of age) were treated with $10 \mathrm{mg} / \mathrm{kg} /$ day Everolimus for 3 days. Everolimus is a derivative of rapamycin and a specific inhibitor of mTOR complex 1 , the complex responsible for mTOR-dependent phosphorylation of S6. ${ }^{33}$ In Everolimus-treated Stat3-IKO littermates pS6 expression was at a level similar to that of control Stat $3^{\mathrm{f} / \mathrm{f}}$ mice (Figure 5, L versus N), whereas strong expression of pS6 was observed as expected in regions of leukocytic infiltration in the colon of untreated Stat3-IKO mice (Figure 50), confirming the effectiveness of the inhibitor. Correlated with the reduced expression of pS6, overproliferation of epithelial cells (measured by Ki-67 expression) was markedly reduced in the colon of Everolimustreated Stat3-IKO mice compared with untreated Stat3-IKO littermates (Figure 5, P versus Q). Indeed, despite the prominent leukocytic infiltration that remained in the area (Figure 5P, arrows), the distribution of $\mathrm{Ki}-67^{+}$cells in the colon of treated mice was similar to that of normal colon, and the cells were generally restricted to the lower half of the gland, as shown in Figure 4B. These results indicate that the mTOR pathway is activated in inflammation-associated colonic epithelium and implicate this activation in the promotion of epithelial cell proliferation.

To confirm the role of inflammation in the activation of Stat3 and mTOR, we assessed activated Stat3 and pS6 in Stat3-IKO mice treated with VNMA to remove intestinal microflora. A marked decrease in both Stat3 activation and pS6 expression was observed in the colonic epithelial cells of VNMA-treated compared with untreated Stat3IKO mice (data not shown).

\section{Regulation of Stat3 Activation in Epithelial Cells in the Inflamed Colon by mTOR}

We next asked whether there was a functional link between MTOR and Stat3 activation in the inflamed colon. We observed that Everolimus treatment of Stat3-IKO mice led to a marked reduction in the activation of Stat3 in colonic epithelial cells, despite the prominent leukocytic infiltration that remained in the area (Figure 6A, arrows). As expected, untreated Stat3-IKO littermates displayed activated Stat3 in colonic epithelial cells surrounded by densely infiltrated leukocytes (Figure 6B). This finding suggests that the activation of Stat3 in inflamed colon was regulated by the activation of mTOR pathway. To determine the potential cross-talk between the mTOR and Stat3 pathways in inflamed colon, we examined the phosphorylation of Stat3 at Ser-727, an event that can be mediated by mTOR as well as by the mitogen-activated protein kinase pathway and is associated with the activation of the transcriptional regulatory activity of Stat3 toward its target genes. ${ }^{35,36}$ Nuclear staining of Stat3 phosphorylated at Ser-727 was observed in the colonic epithelial cells in the inflamed colon of Stat3-IKO mice (Figure 6D), in a pattern similar to that previously observed for the expression of pS6 and activated Stat3. Furthermore, treatment with Everolimus markedly reduced the phosphorylation of Stat3 at Ser-727 in these colonic epithelial cells (Figure 6C). These data indicate that the activation of Stat3 and its downstream factors in colonic epithelial cells during inflammation-induced tumorigenesis is regulated by cross-talk between mTOR and Stat3.

\section{Abnormal Up-Regulation of mTOR-Stat3 Cross- Talk in the Colon of IBD Patients with Active Disease}

To determine whether activation of the mTOR signaling pathway observed in Stat3-IKO mice mimics the inflammatory microenvironment in human IBD, the expression of pS6 in colon samples of four patients with active IBD as well as 40 human sporadic colorectal cancers was examined. IHC revealed positive staining of pS6 in the colonic epithelium in the inflamed colons from each of the four IBD patients, similar to that observed in Stat3-IKO mice. 


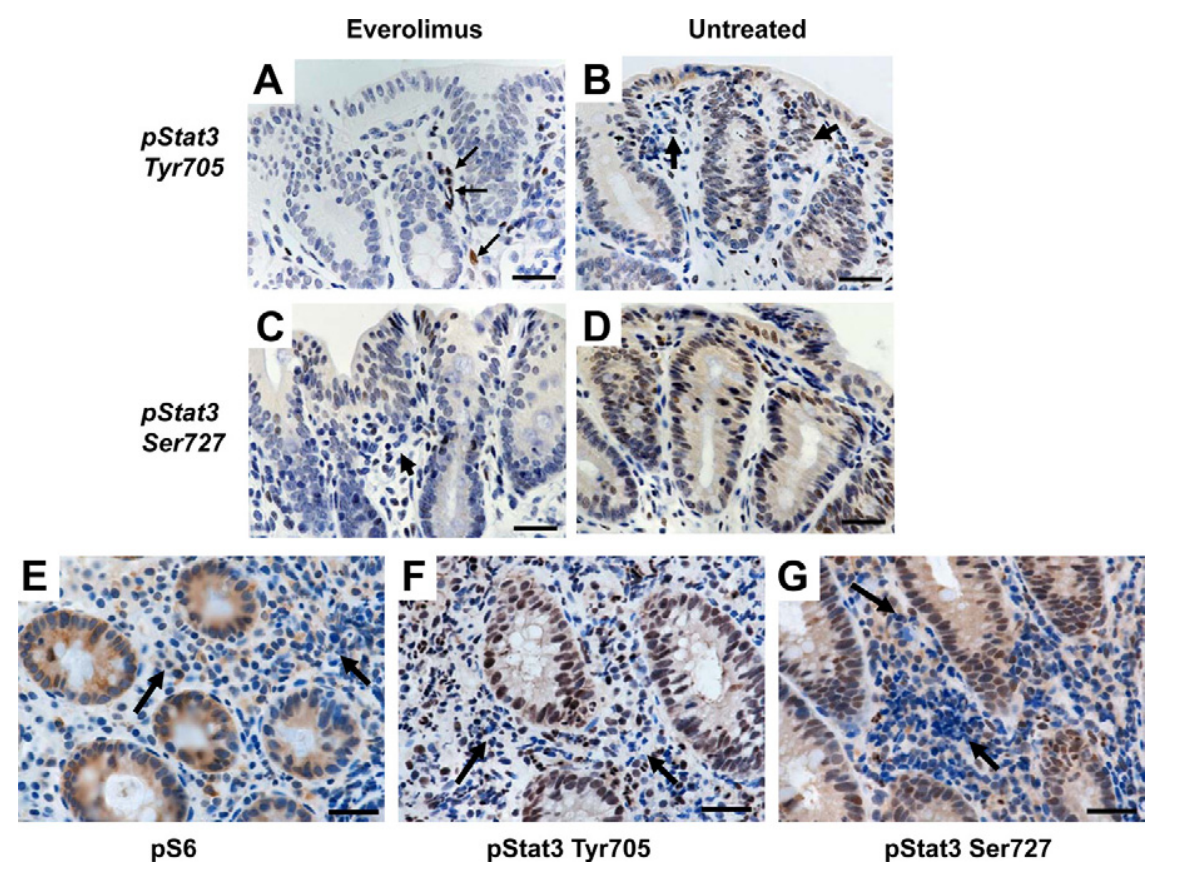

\begin{abstract}
Figure 6. mTOR-Stat 3 cross-talk in human IBD and Stat3-IKO mouse. A-D: mTOR-Stat3 crosstalk in epithelial cells of Stat3-IKO colon. A and B: Immunochemical analysis for phosphorylated Stat3 (pStat3) $\left(\mathrm{Tyr}^{705}\right)$ for colon sections from a Stat3-IKO mouse treated with Everolimus (A) and a untreated Stat3-IKO littermate (B). C and D: Immunochemical analysis for pStat3 (Ser-727) in colon of a Stat3-IKO mouse treated with Everolimus (C) and a untreated Stat3-IKO littermate (D). E-G: Colon sections from human IBD patients. Immunochemical analysis for pS6 (E), pStat3 $\left(\mathrm{Tyr}^{705}\right)(\mathbf{F})$, and pStat3 (Ser-727) (G). Arrows pointed to leukocytic infiltration in the colon sections. Scale bar $=30 \mu \mathrm{m}$.
\end{abstract}

The most intense staining was found in epithelial cells adjacent to areas of dense leukocytic infiltration (Figure 6E). In contrast, more than $80 \%$ of human sporadic colorectal cancer samples and normal colonic glands adjacent to the tumor were negative for pS6 (Supplemental Figure S4, a and b, see http://ajp.amjpathol.org). Six of 40 human sporadic tumor samples displayed a few clusters of pS6-positive cells in the tumor (Supplemental Figure S4, c and d, arrows, see http://ajp.amjpathol.org), and the density and distribution of these positive cells were similar to those observed in normal mouse colon (Figure 5, J and L). These data suggest that the activation of mTOR in colonic epithelial cells is specifically induced by inflammation in the colon of IBD patients. As we observed in Stat3-IKO colons, striking expression of Stat3 phosphorylated at Tyr-705 and Ser727 was found in epithelial cells, often surrounded by prominent infiltration of leukocytes, in the inflamed colon of IBD patients (Figure 6, F and G). These data indicate that the both the mTOR and Stat3 pathways, as well as their crosstalk signaling, are abnormally up-regulated as a result of inflammation in the inflamed colon of human IBD patients. Furthermore, our novel mouse model of inflammation-associated colorectal cancer closely mimics the abnormal signaling observed in colonic epithelium in IBD.

\section{Discussion}

In this study, we establish a novel mouse model of inflammation-associated colorectal cancer by inactivation of Stat3 specifically in hematopoietic cells. Similar to studies using IL10-deficient mice, this model exhibits the development of carcinoma as a consequence of inflammation initiated by immune dysregulation leading to microfloral intolerance, features that mimic human IBD. In contrast to the IL10 deficiency model, however, the new model permits us to observe tumor development in a genetically unmodified colonic epithelium, facilitating mechanistic studies of tumorigenesis. We have exploited this aspect of the model to demonstrate a role for mTORStat3 signaling in inflammation-associated epithelial hyperproliferation and the disruption of epithelial homeostasis. Our findings with respect to mTOR and Stat3 activation in human IBD lend further support to the Stat3IKO model as a mimic of human disease, as does our observation of a frequency of malignant progression in the Stat3-IKO mice similar to that in IBD patients.

Although the pathogenesis of IBD is largely unknown, dysregulation of mucosal immunity, abrogating the normal hyporeactive state with respect to the intestinal microflora, is believed to be the cause of IBD, a high -risk factor for tumor development. ${ }^{37}$ Inactivation of IL-10, a potent anti-inflammatory cytokine, has been closely linked to the development of IBD in humans. ${ }^{6-8} \mathrm{IL}-10$ acts as a potent inhibitor of the activation of macrophages, monocytes, and dendritic cells ${ }^{13}$ as well as the activation and function of natural killer cells and $T$ and $B$ lymphocytes. ${ }^{13}$ Stat3 is a major mediator of signaling downstream of IL-10, as well as that of multiple other cytokines and growth factors. ${ }^{10}$ Several lines of evidence, including a recent genome-wide association study, ${ }^{38,39}$ suggest that Stat3 plays an important role in human IBD and inflammation-associated colorectal cancers. ${ }^{40,41}$ Similar to mice with IL-10 depletion, ${ }^{9}$ mice in which Stat3 was depleted in myeloid cells via LysM- or Mx1 promoterdriven Cre expression develop colonic inflammation, ${ }^{11,42}$ indicating that $\mathrm{IL}-10$ plays a critical role in regulating mucosal immunity in colon and IL-10 exerts its action through Stat3 expressed in myeloid cells. Mice with Stat3 inactivation in myeloid cells had enhanced Th1 activity and were highly susceptible to endotoxin shock, with increased production of inflammatory cytokines. ${ }^{12}$ We also found consistently that macrophages isolated from 
Stat3-IKO mice overproduced proinflammatory cytokines, including tumor necrosis factor- $\alpha$, IL-6, and IL-1 $\alpha$ and $\beta$, when treated with the bacterial membrane component lipopolysaccharide (data not shown). Inflammatory macrophages are known to produce an array of cytokines and chemokines that promote infiltration and activation of other leukocytes, including lymphocytes, and that also promote angiogenesis, cell proliferation, and tissue damage. ${ }^{43,44}$ However, unlike $I L-10^{-/-}$mice, in which malignant tumors develop in the inflamed intestine, ${ }^{9}$ no tumors were reported in mice with $L y s M$ - or Mx1-Cre-mediated Stat3 inactivation in myeloid cells. In contrast, we demonstrate the development of malignancy in Stat3-IKO mice, suggesting that Stat3 in both myeloid and lymphoid cells may serve as a control point for the development of malignant intestinal tumors. Because mice with T lymphocyte-specific depletion of Stat3 develop neither colitis nor colonic tumors, ${ }^{14}$ it is possible that cross-talk among stromal cells is needed for the promotion of tumorigenesis. Alternatively, differences between Csf1r and LysM promoter activation of the Cre recombinase in myeloid cells may account for the enhanced tumorigenesis in Stat3-IKO mice. The expression of LysM is chiefly in mature macrophages and neutrophils, ${ }^{45-47}$ whereas activation of the Csf1r promoter is initiated at an earlier stage of the myeloid lineage, although the activity in mature granulocytes is weak. ${ }^{16}$ Thus, the Csf1r promoter may direct Stat3 depletion to a different and perhaps broader range of myeloid cells compared with LysM, modulating the function of subpopulations of myeloid cells involved in tumor development. In addition, the difference between these prompters can be a matter of efficacy.

Although Csf1r-Cre led to a highly efficient inactivation of Stat3 in bone marrow-derived macrophages, we observed a high density of mononuclear cells with activated Stat3 among infiltrated stromal cells in the inflamed colon of Stat3-IKO mice, consistent with observations in human IBD colons that a large percentage of infiltrated $\mathrm{CD}^{+} 8^{+}$ macrophages and $\mathrm{CD}^{+}$lymphocytes expressed activated Stat3. ${ }^{48-50}$ The subtypes of myeloid and lymphoid cells in which Stat3 is inactivated or, in contrast, in which Stat3 is activated in the inflamed colon in Stat3-IKO mice, has not yet been determined. We anticipate that resolution of this issue will identify a population of myeloid/ lymphoid cells that plays a key role in regulating homeostasis of mucosal immunity in the colon, with the consequence that disrupting the function of these cells initiates inflammation, and that different population(s) of leukocytes, with intact Stat3 that can respond to cytokines produced at the inflammatory site (eg, IL-6, IL-12, IL-10, vascular endothelial growth factor, and IL-23 that signal through Stat $3^{50,51}$ ), will respond to this cue that prompts their infiltration into the colon.

Consistent with findings in human IBD and IL-10-deficient mice, ${ }^{2}$ our study demonstrates that microflora plays a fundamental role in the development of inflammation in the colon. The response to antibiotic treatment and the increased density of bacteria in the stool of Stat3-IKO mice demonstrate quantitative and possible qualitative changes in the populations of microflora and reduced antibacterial ability of the mucosal immune system in this model. Recent studies have shown that the network of IL-23, IL-22, and IL-17 plays an important role in mucosal antimicrobial activities. ${ }^{52,53}$ On the stimulation of bacteria, dendritic cells can produce IL-22 directly or indirectly through activation of Th17 with IL-6 and IL-23 that promotes the antibacterial activities in the epithelial barrier. ${ }^{52,53}$ In the normal situation, when the inflammatory stimulus is removed, IL-10 and transforming growth factor- $\beta$ are believed to play an immune-suppressive role to resolve the inflammation. ${ }^{51}$ Interestingly, most of the cytokines involved in this process, including IL-10, IL-6, IL-23, and IL-22, mediate their signals through Stat3. ${ }^{51-54}$. It is possible that inactivation of Stat3 in certain myeloid/lymphoid cells in Stat3-IKO mice perturbs this regulation and compromises the epithelial barrier, which may induce changes in the normal populations of microflora and even lead to expansion of pathogenic bacteria. In addition, the persistent inflammation, which is often accompanied by overproduction of various proteinases, reactive oxygen, and nitrogen, may physically damage the epithelial barrier in Stat3-IKO mice. The potential disruption of the IL-23/Th17 axis, which was shown to regulate restitution and repair in intestinal epithelium, ${ }^{51}$ by Stat3 inactivation may further enhance the damage of the epithelial barrier and cause the invasion of pathogenic bacteria. Therefore, it is likely that interruption of the intestinal epithelial barrier occurs in the colon of Stat3-IKO mice, which may promote bacterial translocation into mucosa and submucosa with subsequent infiltration of leukocytes and augmented inflammation.

A large percentage of Stat3-IKO mice developed hyperplastic and dysplastic lesions in the colon, with $\sim 16 \%$ of the mice progressing to invasive carcinoma, a phenotype always associated with more extensive inflammation. Compared with other commonly used mouse models of inflammation-associated colorectal cancers, the frequency of carcinoma development in the Stat3-IKO mice is relatively low, but it is close to the 18 to $20 \%$ tumor incidence in human IBD patients, which is similarly associated with prolonged and extensive colitis. ${ }^{55-57}$ In other widely used mouse models of chemically induced inflammation-associated colorectal cancer, nearly $100 \%$ of mice develop colon tumors. ${ }^{58-60}$ Although it is convenient for conducting investigations with these models, the inflammation is acute, resulting from mucosal damage, which may not recapitulate stochastic events involved in inflammation-associated cancers in the human. ${ }^{4}$ In contrast, tumors in Stat3-IKO mice are induced by spontaneous chronic inflammation, which may more closely model the dysregulation of mucosal immunity in the etiology of human IBD. ${ }^{2}$ The finding that treating Stat3-IKO mice with antibiotics reduced colonic inflammation, accompanied by a similar reduction in early stage tumor lesions, suggests that inflammation is a causal factor for the tumor development and persistence in the colon. This finding is consistent with previous reports that use of nonsteroidal anti-inflammatory drugs and treatment of experimental animal models with cyclooxygenase 2 or nuclear factor- $\kappa$ B inhibitors to inhibit inflammation lead to tumor regression. ${ }^{61-63}$ Our findings also further demon- 
strate that tumor development in Stat3-IKO mice is caused by the abnormal mucosal immune response to microflora, as proposed for the pathogenesis of human IBD and associated colorectal cancers. ${ }^{2}$

By specifically targeting Stat3 depletion to the stromal compartment, the Stat3-IKO model, unlike IL-10-deficient models, allowed us to demonstrate that genetic disturbance of homeostasis in this compartment is sufficient for inflammation-associated tumorigenesis. Conversely, by preserving Stat3 function in epithelial cells, we were able to observe that epithelial Stat3, which is activated in human tumors associated with inflammation, ${ }^{64-66}$ was indeed activated in tumors of Stat3-IKO mice. Stat3 is persistently active in various human malignancies and possesses oncogenic potential, ${ }^{30}$ and the activation of Stat3 in human colorectal cancer cells is regulated by the tumor stroma. ${ }^{67}$ Stat3 can be activated by many cytokines and growth factors commonly produced in inflammation, including IL-6, vascular endothelial growth factor, colony-stimulating factor-1, IL-23, IL-22, and endothelial growth factor. ${ }^{30,51,68}$ Because IL-10 is a potent inhibitor of the expression of many of these factors in macrophages, ${ }^{69}$ blocking the signal from IL-10 by inactivating Stat3 in macrophages may promote the overproduction of these cytokines and lead to inflammation, as observed in Stat3-IKO mice. As mentioned above, IL-22, which activates epithelial Stat3, may be overproduced by several immune cells when abnormal antibacterial activity is induced in intestinal mucosa. ${ }^{70}$ Therefore, multiple factors in the inflamed colon of Stat3-IKO mice may cause the persistent activation of Stat3 in epithelial cells. Overexpression of cyclin D1, Survivin, and Bcl-xL, all targets of Stat3, was present in the inflamed regions and in tumors of the Stat3-IKO mice. The expression of these markers has been linked to abnormal cell proliferation and survival and subsequent phenotypes of malignant transformation, ${ }^{32,71-73}$ further demonstrating the significance of Stat3 activation in tumorigenesis in colon and supporting the hypothesis that overproliferation of colonic epithelial cells observed in Stat3-IKO colon is due to the activation of the Stat3 pathway in these cells. The importance of Stat3 in tumor development in an inflammatory microenvironment of the intestine is emphasized by recent studies using dextran sulfate sodium-induced colitis/tumor mouse models with targeted inactivation of Stat3 in intestinal epithelial cells. ${ }^{74,75}$ The dichotomy between the potential beneficial effects of inactivating Stat3 in tumor epithelial cells and stimulation of an inflammatory response by inactivation in the stroma would have to be considered in therapeutic strategies that have been suggested for targeting Stat3. ${ }^{76-78}$

mTOR is a critical effector regulating cell growth and dysregulation of this pathway has been found in many human diseases, including type II diabetes and various malignancies. ${ }^{33,79-81}$ However, a role for mTOR in inflammation-associated tumorigenesis has not previously been demonstrated, and mTOR activation has not been described in inflamed colonic epithelium either in animal models or in human disease. It is therefore notable that mTOR activation, dependent on the presence of intestinal microflora, is a prominent feature of inflammation-associ- ated epithelium in Stat3-IKO mice, and that epithelial hyperproliferation is mTOR-dependent. It is possible that these unique features of the Stat3-IKO model are related to our observation of inflammation-dependent malignancy in these mice.

Aberrant activation of mTOR in cancer is probably due to deregulation of factors that regulate mTOR activity, because activating mutations in mTOR have not been identified. ${ }^{82}$ Signaling through extracellular signal-regulated kinase has been implicated in the activation of mTOR in human tumors, ${ }^{83}$ and activation of mitogenactivated protein kinase/extracellular signal-regulated kinase, linked to tumor necrosis factor- $\alpha$ signaling, has been noted in the inflamed mucosa of IBD patients. ${ }^{84}$ However, mTOR activation has not previously been described in this setting. Our findings demonstrate that mTOR activation is not a general feature of human colorectal tumors but is present in IBD and is specifically localized to inflammation-associated epithelium, thus paralleling our observations in Stat3-IKO mice. These data provide strong support for the utility of the Stat3-IKO model in the investigation of inflammation-associated tumorigenesis.

The cross-talk between mTOR and Stat3 is important in several physiological and malignant conditions, including myelin-associated inhibitor-promoted differentiation of neural progenitors, ${ }^{85}$ the maintenance of the viability of breast cancer stem-like cells, ${ }^{86}$ AKT-enhanced proliferation of human glioblastomas, ${ }^{87}$ and IL-6-induced hepatic insulin resistance. ${ }^{88}$ Here we provide evidence that mTOR acts as an upstream regulator for the activation of Stat3 in epithelial cells in the inflamed region of both human IBD and Stat3-IKO colons. Further studies of the interaction between mTOR and Stat3 signaling are therefore a promising approach for the elucidation of mechanisms of tumorigenesis in the inflamed intestine.

The factors that generate mTOR-Stat3 activation in epithelial cells in response to inflammation in Stat3-IKO mice have not been determined. A recent study in an irritant-induced colitis model provided evidence for IL-6 as a link between inflammation and Stat3 activation. ${ }^{74}$ The authors did not observe a dependence of mTOR activation on IL-6. It is possible that Stat3 activity represents the combined effect of IL-6 and a parallel pathway, yet to be determined, that regulates mTOR. Alternatively, because IL-6 is capable of up-regulating mTOR signaling $^{88}$, the role of mTOR as an IL-6 effector may be dependent on the model studied. Future studies will be directed to the elucidation of factors governing the activation of these pathways in the inflamed colon. Although the etiology of IBD is not clear, interaction of the intestinal microflora with the gut immune system probably plays an important role. 2,89,90 The data presented here suggest that the novel model established in this study mimics the modulation of the intestinal mucosal immune response by a complex interplay of genetic, microbial, and environmental factors in human IBD and points to mTOR as a potentially key mediator of these interactions. 


\section{Acknowledgments}

We thank Dr. Rolf Sprengel (Max-Planck Institute for Medical Research) for the iCre fragment, Dr. Colin Stewart $(\mathrm{NIH})$ for Stat3 ${ }^{\text {flox/flox }}$ mice, and Dr. Matthias M. Stadtfeld (Harvard Stem Cell Institute) for Rosa26-YFP mice. We thank Drs. Sandra Guilmeau, Marta Flandez-Canet, Lidija Klampfer, Anna Velcich, Ken Chen, Robert Odze, Kathryn E. Tanaka, and Larry Herbst for useful discussions; Michelle Houston, Elena Dhima, Mark Thomas, and James Lee for excellent technical support; the technical staffs of the AnaIytical Imaging Facility, Histotechnology and Comparative Pathology Facility, Transgenic Mouse Facility, and Fluorescence Activated Cell Sorter Facility of the Albert Einstein College of Medicine; and Mary Larocca and Kerry Victor for administrative support.

\section{References}

1. Itzkowitz SH, Yio X: Inflammation and cancer IV. Colorectal cancer in inflammatory bowel disease: the role of inflammation. Am J Physiol Gastrointest Liver Physiol 2004, 287:G7-G17

2. Strober W, Fuss I, Mannon P: The fundamental basis of inflammatory bowel disease. J Clin Invest 2007, 117:514-521

3. Wirtz S, Neurath MF: Mouse models of inflammatory bowel disease Adv Drug Deliv Rev 2007, 59:1073-1083

4. Kawada M, Arihiro A, Mizoguchi E: Insights from advances in research of chemically induced experimental models of human inflammatory bowel disease. World J Gastroenterol 2007, 13:5581-5593

5. Rennick DM, Fort MM, Davidson NJ: Studies with IL-10 ${ }^{-1-}$ mice: an overview. J Leukoc Biol 1997, 61:389-396

6. Marrakchi R, Moussa A, Ouerhani S, Bougatef K, Bouhaha R, Messai Y, Rouissi K, Khadimallah I, Khodjet-El-Khil H, Najar T, BenammarElgaaeid A: Interleukin 10 promoter region polymorphisms in inflammatory bowel disease in Tunisian population. Inflamm Res 2009, 58:155-160

7. Franke A, Balschun T, Karlsen TH, Sventoraityte J, Nikolaus S, Mayr G, Domingues FS, Albrecht M, Nothnagel M, Ellinghaus D, Sina C, Onnie CM, Weersma RK, Stokkers PC, Wijmenga C, Gazouli M, Strachan D, McArdle WL, Vermeire S, Rutgeerts P, Rosenstiel P, Krawczak M, Vatn MH, Mathew CG, Schreiber S: Sequence variants in IL10. ARPC2 and multiple other loci contribute to ulcerative colitis susceptibility. Nat Genet 2008, 40:1319-1323

8. Sanchez R, Levy E, Costea F, Sinnett D: IL-10 and TNF- $\alpha$ promoter haplotypes are associated with childhood Crohn's disease location. World J Gastroenterol 2009, 15:3776-3782

9. Berg DJ, Davidson N, Kuhn R, Muller W, Menon S, Holland G, Thompson-Snipes L, Leach MW, Rennick D: Enterocolitis and colon cancer in interleukin-10-deficient mice are associated with aberrant cytokine production and $\mathrm{CD}^{+}{ }^{+} \mathrm{TH} 1$-like responses. J Clin Invest 1996, 98:1010-1020

10. Lang R: Tuning of macrophage responses by Stat3-inducing cytokines: molecular mechanisms and consequences in infection. Immunobiology 2005, 210:63-76

11. Alonzi T, Newton IP, Bryce PJ, Di Carlo E, Lattanzio G, Tripodi M Musiani $P$, Poli V: Induced somatic inactivation of STAT3 in mice triggers the development of a fulminant form of enterocolitis. Cytokine 2004, 26:45-56

12. Takeda K, Clausen BE, Kaisho T, Tsujimura T, Terada N, Forster I, Akira S: Enhanced Th1 activity and development of chronic enterocolitis in mice devoid of Stat3 in macrophages and neutrophils. Immunity 1999, 10:39-49

13. Moore KW, de Waal Malefyt R, Coffman RL, O'Garra A: Interleukin-10 and the interleukin-10 receptor. Annu Rev Immunol 2001, 19:683-765

14. Takeda K, Kaisho T, Yoshida N, Takeda J, Kishimoto T, Akira S: Stat3 activation is responsible for IL-6-dependent $T$ cell proliferation through preventing apoptosis: generation and characterization of $\mathrm{T}$ cell-specific Stat3-deficient mice. J Immunol 1998, 161:4652-4660

15. Sasmono RT, Ehrnsperger A, Cronau SL, Ravasi T, Kandane R,
Hickey MJ, Cook AD, Himes SR, Hamilton JA, Hume DA: Mouse neutrophilic granulocytes express mRNA encoding the macrophage colony-stimulating factor receptor (CSF-1R) as well as many other macrophage-specific transcripts and can transdifferentiate into macrophages in vitro in response to CSF-1. J Leukoc Biol 2007, 82:111-123

16. Sasmono RT, Oceandy D, Pollard JW, Tong W, Pavli P, Wainwright BJ, Ostrowski MC, Himes SR, Hume DA: A macrophage colonystimulating factor receptor-green fluorescent protein transgene is expressed throughout the mononuclear phagocyte system of the mouse. Blood 2003, 101:1155-1163

17. Shimshek DR, Kim J, Hubner MR, Spergel DJ, Buchholz F, Casanova E, Stewart AF, Seeburg PH, Sprengel R: Codon-improved Cre recombinase (iCre) expression in the mouse. Genesis 2002, 32:19-26

18. Raz R, Lee CK, Cannizzaro LA, d'Eustachio P, Levy DE: Essential role of STAT3 for embryonic stem cell pluripotency. Proc Natl Acad Sci USA: 1999, 96:2846-2851

19. Lin EY, Orlofsky A, Berger MS, Prystowsky MB: Characterization of A1, a novel hemopoietic-specific early-response gene with sequence similarity to bcl-2. J Immunol 1993, 151:1979-1988

20. Boivin GP, Washington K, Yang K, Ward JM, Pretlow TP, Russell R, Besselsen DG, Godfrey VL, Doetschman T, Dove WF, Pitot HC, Halberg RB, Itzkowitz SH, Groden J, Coffey RJ: Pathology of mouse models of intestinal cancer: consensus report and recommendations. Gastroenterology 2003, 124:762-777

21. Xiao H, Gulen MF, Qin J, Yao J, Bulek K, Kish D, Altuntas CZ, Wald D, Ma C, Zhou H, Tuohy VK, Fairchild RL, de la Motte C, Cua D, Vallance BA, Li X: The Toll-interleukin-1 receptor member SIGIRR regulates colonic epithelial homeostasis, inflammation, and tumorigenesis. Immunity 2007, 26:461-475

22. Lin EY, Li JF, Gnatovskiy L, Deng Y, Zhu L, Grzesik DA, Qian H, Xue $\mathrm{XN}$, Pollard JW: Macrophages regulate the angiogenic switch in a mouse model of breast cancer. Cancer Res 2006, 66:11238-11246

23. Odze R: Diagnostic problems and advances in inflammatory bowel disease. Mod Pathol 2003, 16:347-358

24. Blackstone MO, Riddell RH, Rogers BH, Levin B: Dysplasia-associated lesion or mass (DALM) detected by colonoscopy in long-standing ulcerative colitis: an indication for colectomy. Gastroenterology 1981, 80:366-374

25. Rautava S, Walker WA: Commensal bacteria and epithelial cross talk in the developing intestine. Curr Gastroenterol Rep 2007, 9:385-392

26. Baumgart DC: What's new in inflammatory bowel disease in 2008 ? World J Gastroenterol 2008, 14:329-330

27. van Es JH, van Gijn ME, Riccio O, van den Born M, Vooijs M, Begthel H, Cozijnsen M, Robine S, Winton DJ, Radtke F, Clevers H: Notch/ $\gamma$-secretase inhibition turns proliferative cells in intestinal crypts and adenomas into goblet cells. Nature 2005, 435:959-963

28. Velcich A, Yang W, Heyer J, Fragale A, Nicholas C, Viani S, Kucherlapati R, Lipkin M, Yang K, Augenlicht L: Colorectal cancer in mice genetically deficient in the mucin Muc2. Science 2002, 295:1726-1729

29. Yang K, Popova NV, Yang WC, Lozonschi I, Tadesse S, Kent S Bancroft L, Matise I, Cormier RT, Scherer SJ, Edelmann W, Lipkin M, Augenlicht L, Velcich A: Interaction of Muc2 and Apc on Wnt signaling and in intestinal tumorigenesis: potential role of chronic inflammation. Cancer Res 2008, 68:7313-7322

30. Yu H, Kortylewski M, Pardoll D: Crosstalk between cancer and immune cells: role of STAT3 in the tumour microenvironment. Nat Rev Immunol 2007, 7:41-51

31. Mita AC, Mita MM, Nawrocki ST, Giles FJ: Survivin: key regulator of mitosis and apoptosis and novel target for cancer therapeutics. Clin Cancer Res 2008, 14:5000-5005

32. Altieri DC: Survivin, cancer networks and pathway-directed drug discovery. Nat Rev Cancer 2008, 8:61-70

33. Petroulakis E, Mamane $Y$, Le Bacquer O, Shahbazian D, Sonenberg $\mathrm{N}$ : mTOR signaling: implications for cancer and anticancer therapy. Br J Cancer 2006, 94:195-199

34. Mamane Y, Petroulakis E, LeBacquer O, Sonenberg N: mTOR, translation initiation and cancer. Oncogene 2006, 25:6416-6422

35. Wen Z, Zhong Z, Darnell JE Jr: Maximal activation of transcription by Stat1 and Stat3 requires both tyrosine and serine phosphorylation. Cell 1995, 82:241-250

36. Yokogami K, Wakisaka S, Avruch J, Reeves SA: Serine phosphorylation and maximal activation of STAT3 during CNTF signaling is mediated by the rapamycin target mTOR. Curr Biol 2000, 10:47-50 
37. Podolsky DK: Inflammatory bowel disease. N Engl J Med 2002, 347:417-429

38. Barrett JC, Hansoul S, Nicolae DL, Cho JH, Duerr RH, Rioux JD, Brant SR, Silverberg MS, Taylor KD, Barmada MM, Bitton A, Dassopoulos T, Datta LW, Green T, Griffiths AM, Kistner EO, Murtha MT, Regueiro MD, Rotter JI, Schumm LP, Steinhart AH, Targan SR, Xavier RJ, Libioulle C, Sandor C, Lathrop M, Belaiche J, Dewit O, Gut I, Heath S, Laukens D, Mni M, Rutgeerts P, Van Gossum A, Zelenika D, Franchimont D, Hugot JP, de Vos M, Vermeire S, Louis E, Cardon LR, Anderson CA, Drummond H, Nimmo E, Ahmad T, Prescott NJ, Onnie CM, Fisher SA, Marchini J, Ghori J, Bumpstead S, Gwilliam R, Tremelling M, Deloukas P, Mansfield J, Jewell D, Satsangi J, Mathew CG, Parkes M, Georges M, Daly MJ: Genome-wide association defines more than 30 distinct susceptibility loci for Crohn's disease. Nat Genet 2008, 40:955-962

39. Anderson CA, Massey DC, Barrett JC, Prescott NJ, Tremelling M, Fisher SA, Gwilliam R, Jacob J, Nimmo ER, Drummond H, Lees CW, Onnie CM, Hanson C, Blaszczyk K, Ravindrarajah R, Hunt S, Varma D, Hammond N, Lewis G, Attlesey H, Watkins N, Ouwehand W, Strachan D, McArdle W, Lewis CM, Lobo A, Sanderson J, Jewell DP, Deloukas P, Mansfield JC, Mathew CG, Satsangi J, Parkes M: Investigation of Crohn's disease risk loci in ulcerative colitis further defines their molecular relationship. Gastroenterology 2009, 136:523-529

40. Sugimoto K: Role of STAT3 in inflammatory bowel disease. World $J$ Gastroenterol 2008, 14:5110-5114

41. Fu XY: STAT3 in immune responses and inflammatory bowel diseases. Cell Res 2006, 16:214-219

42. Kobayashi M, Kweon MN, Kuwata H, Schreiber RD, Kiyono H, Takeda K, Akira S: Toll-like receptor-dependent production of IL-12p40 causes chronic enterocolitis in myeloid cell-specific Stat3-deficient mice. J Clin Invest 2003, 111:1297-1308

43. Coussens LM, Werb Z: Inflammation and cancer. Nature 2002, 420:860-867

44. Sanchez-Munoz F, Dominguez-Lopez A, Yamamoto-Furusho JK: Role of cytokines in inflammatory bowel disease. World J Gastroenterol 2008, 14:4280-4288

45. Cross M, Mangelsdorf I, Wedel A, Renkawitz R: Mouse lysozyme M gene: isolation, characterization, and expression studies. Proc Natl Acad Sci USA: 1988, 85:6232-6236

46. Faust N, Varas F, Kelly LM, Heck S, Graf T: Insertion of enhanced green fluorescent protein into the lysozyme gene creates mice with green fluorescent granulocytes and macrophages. Blood 2000, 96:719-726

47. Goren I, Allmann N, Yogev N, Schurmann C, Linke A, Holdener M, Waisman A, Pfeilschifter J, Frank S: A transgenic mouse model of inducible macrophage depletion: effects of diphtheria toxin-driven lysozyme M-specific cell lineage ablation on wound inflammatory, angiogenic, and contractive processes. Am J Pathol 2009, 175:132-147

48. Musso A, Dentelli P, Carlino A, Chiusa L, Repici A, Sturm A, Fiocchi C, Rizzetto M, Pegoraro L, Sategna-Guidetti C, Brizzi MF: Signal transducers and activators of transcription 3 signaling pathway: an essential mediator of inflammatory bowel disease and other forms of intestinal inflammation. Inflamm Bowel Dis 2005, 11:91-98

49. Carey R, Jurickova I, Ballard E, Bonkowski E, Han X, Xu H, Denson LA: Activation of an IL-6:STAT3-dependent transcriptome in pediatric-onset inflammatory bowel disease. Inflamm Bowel Dis 2008, 14:446-457

50. Atreya R, Mudter J, Finotto S, Mullberg J, Jostock T, Wirtz S, Schutz M, Bartsch B, Holtmann M, Becker C, Strand D, Czaja J, Schlaak JF, Lehr HA, Autschbach F, Schurmann G, Nishimoto N, Yoshizaki K, Ito H, Kishimoto T, Galle PR, Rose-John S, Neurath MF: Blockade of interleukin 6 trans signaling suppresses T-cell resistance against apoptosis in chronic intestinal inflammation: evidence in Crohn disease and experimental colitis in vivo. Nat Med 2000, 6:583-588

51. Maloy KJ, Kullberg MC: IL-23 and Th17 cytokines in intestinal homeostasis. Mucosal Immunol 2008, 1:339-349

52. Ouyang W, Kolls JK, Zheng Y: The biological functions of T helper 17 cell effector cytokines in inflammation. Immunity 2008, 28:454-467

53. Laurence A, O'Shea JJ, Watford WT: Interleukin-22: a sheep in wolf's clothing. Nat Med 2008, 14:247-249

54. Murray PJ: The JAK-STAT signaling pathway: input and output integration. J Immunol 2007, 178:2623-2629

55. Burstein E, Fearon ER: Colitis and cancer: a tale of inflammatory cells and their cytokines. J Clin Invest 2008, 118:464-467
56. Xie J, Itzkowitz SH: Cancer in inflammatory bowel disease. World $J$ Gastroenterol 2008, 14:378-389

57. Chan EP, Lichtenstein GR: Chemoprevention: risk reduction with medical therapy of inflammatory bowel disease. Gastroenterol Clin North Am 2006, 35:675-712

58. Morris GP, Beck PL, Herridge MS, Depew WT, Szewczuk MR, Wallace $\mathrm{JL}$ : Hapten-induced model of chronic inflammation and ulceration in the rat colon. Gastroenterology 1989, 96:795-803

59. Okayasu I, Hatakeyama S, Yamada M, Ohkusa T, Inagaki Y, Nakaya R: A novel method in the induction of reliable experimental acute and chronic ulcerative colitis in mice. Gastroenterology 1990, 98:694-702

60. Boirivant M, Fuss IJ, Chu A, Strober W: Oxazolone colitis: a murine model of $T$ helper cell type 2 colitis treatable with antibodies to interleukin 4. J Exp Med 1998, 188:1929-1939

61. Mulcahy HE, O'Donoghue D: Nonsteroidal anti-inflammatory drugs and their colonic effects: more interesting than irritating?. Eur J Gastroenterol Hepatol 2002, 14:1177-1178

62. Jacoby RF, Seibert K, Cole CE, Kelloff G, Lubet RA: The cyclooxygenase-2 inhibitor celecoxib is a potent preventive and therapeutic agent in the min mouse model of adenomatous polyposis. Cancer Res 2000, 60:5040-5044

63. Luo JL, Maeda S, Hsu LC, Yagita H, Karin M: Inhibition of NF- $\kappa$ B in cancer cells converts inflammation- induced tumor growth mediated by TNF $\alpha$ to TRAIL-mediated tumor regression. Cancer Cell 2004, 6:297-305

64. Abou-Ghazal M, Yang DS, Qiao W, Reina-Ortiz C, Wei J, Kong LY, Fuller GN, Hiraoka N, Priebe W, Sawaya R, Heimberger AB: The incidence, correlation with tumor-infiltrating inflammation, and prognosis of phosphorylated STAT3 expression in human gliomas. Clin Cancer Res 2008, 14:8228-8235

65. Berasain C, Castillo J, Perugorria MJ, Latasa MU, Prieto J, Avila MA: Inflammation and liver cancer: new molecular links. Ann NY Acad Sci 2009, 1155:206-221

66. Starska K, Brys M, Forma E, Glowacka E, Lewy-Trenda I, Stasikowska O, Krajewska WM, Lukomski M: Impact of EGFR immunoexpression on STAT3 activation and association with proinflammatory/regulatory cytokine pattern in laryngeal squamous cell carcinoma. Oncol Rep 2009, 21:539-548

67. Corvinus FM, Orth C, Moriggl R, Tsareva SA, Wagner S, Pfitzner EB, Baus D, Kaufmann R, Huber LA, Zatloukal K, Beug H, Ohlschlager P, Schutz A, Halbhuber KJ, Friedrich K: Persistent STAT3 activation in colon cancer is associated with enhanced cell proliferation and tumor growth. Neoplasia 2005, 7:545-555

68. Atreya R, Neurath MF: Involvement of IL-6 in the pathogenesis of inflammatory bowel disease and colon cancer. Clin Rev Allergy Immunol 2005, 28:187-196

69. Couper KN, Blount DG, Riley EM: IL-10: the master regulator of immunity to infection. J Immunol 2008, 180:5771-5777

70. Ouyang W, Valdez P: IL-22 in mucosal immunity. Mucosal Immunol 2008, 1:335-338

71. Hulit J, Wang C, Li Z, Albanese C, Rao M, Di Vizio D, Shah S, Byers SW, Mahmood R, Augenlicht LH, Russell R, Pestell RG: Cyclin D1 genetic heterozygosity regulates colonic epithelial cell differentiation and tumor number in ApcMin mice. Mol Cell Biol 2004, 24:7598-7611

72. Adams JM, Cory S: The Bcl-2 apoptotic switch in cancer development and therapy. Oncogene 2007, 26:1324-1337

73. Alao JP: The regulation of cyclin D1 degradation: roles in cancer development and the potential for therapeutic invention. Mol Cancer 2007, 6:24

74. Grivennikov S, Karin E, Terzic J, Mucida D, Yu GY, Vallabhapurapu S, Scheller J, Rose-John S, Cheroutre H, Eckmann L, Karin M: IL-6 and Stat3 are required for survival of intestinal epithelial cells and development of colitis-associated cancer. Cancer Cell 2009, 15:103-113

75. Bollrath J, Phesse TJ, von Burstin VA, Putoczki T, Bennecke M, Bateman T, Nebelsiek T, Lundgren-May T, Canli O, Schwitalla S, Matthews V, Schmid RM, Kirchner T, Arkan MC, Ernst M, Greten FR: gp130-mediated Stat3 activation in enterocytes regulates cell survival and cell-cycle progression during colitis-associated tumorigenesis. Cancer Cell 2009, 15:91-102

76. He M, Young CY: New approaches to target the androgen receptor and STAT3 for prostate cancer treatments. Mini Rev Med Chem 2009, 9:395-400 
77. Heimberger AB, Priebe W: Small molecular inhibitors of p-STAT3: novel agents for treatment of primary and metastatic CNS cancers. Recent Pat CNS Drug Discov 2008, 3:179-188

78. Costantino L, Barlocco D: STAT 3 as a target for cancer drug discovery. Curr Med Chem 2008, 15:834-843

79. Dann SG, Selvaraj A, Thomas G: mTOR Complex1-S6K1 signaling: at the crossroads of obesity, diabetes and cancer. Trends Mol Med 2007, 13:252-259

80. Le Tourneau C, Faivre S, Serova M, Raymond E: mTORC1 inhibitors: is temsirolimus in renal cancer telling us how they really work? $\mathrm{Br} \mathrm{J}$ Cancer 2008, 99:1197-1203

81. Faivre S, Kroemer G, Raymond E: Current development of mTOR inhibitors as anticancer agents. Nat Rev Drug Discov 2006, 5:671-688

82. Memmott RM, Dennis PA: Akt-dependent and -independent mechanisms of mTOR regulation in cancer. Cell Signal 2009, 21:656-664

83. Ma L, Chen Z, Erdjument-Bromage H, Tempst P, Pandolfi PP: Phosphorylation and functional inactivation of TSC2 by Erk implications for tuberous sclerosis and cancer pathogenesis. Cell 2005, 121:179-193

84. Waetzig GH, Seegert D, Rosenstiel P, Nikolaus S, Schreiber S: p38 mitogen-activated protein kinase is activated and linked to TNF- $\alpha$ signaling in inflammatory bowel disease. J Immunol 2002, 168:5342-5351

85. Wang B, Xiao Z, Chen B, Han J, Gao Y, Zhang J, Zhao W, Wang X Dai J: Nogo-66 promotes the differentiation of neural progenitors into astroglial lineage cells through mTOR-STAT3 pathway. PLoS ONE 2008, 3:e1856

86. Zhou J, Wulfkuhle J, Zhang H, Gu P, Yang Y, Deng J, Margolick JB, Liotta LA, Petricoin E, 3rd, Zhang Y: Activation of the PTEN/mTOR/STAT3 pathway in breast cancer stem-like cells is required for viability and maintenance. Proc Natl Acad Sci USA: 2007, 104:16158-16163

87. Riemenschneider MJ, Betensky RA, Pasedag SM, Louis DN: AKT activation in human glioblastomas enhances proliferation via TSC2 and S6 kinase signaling. Cancer Res 2006, 66:5618-5623

88. Kim JH, Kim JE, Liu HY, Cao W, Chen J: Regulation of interleukin-6induced hepatic insulin resistance by mammalian target of rapamycin through the STAT3-SOCS3 pathway. J Biol Chem 2008, 283:708-715

89. Sands BE: Inflammatory bowel disease: past, present, and future. J Gastroenterol 2007, 42:16-25

90. Xavier RJ, Podolsky DK: Unravelling the pathogenesis of inflammatory bowel disease. Nature 2007, 448:427-434 